\title{
How do travellers respond to health and environmental policies to reduce air pollution?
}

\author{
Caroline Orset*
}

\begin{abstract}
Despite the various measures taken to reduce air pollution in France, the French continue to use high-emission vehicles. We propose to evaluate the willingness to pay (WTP) for four means of transport: two high-emission vehicles (diesel taxi and diesel personal vehicle) and two low-emission vehicles (rented electric vehicle and public transport). Successive messages revealing the effects of air pollution on health and the environment are provided to individuals in a different order. The information conveyed changes both of the WTP of individuals and of their choices. However, the use of high-emission vehicles has not diminished, personal vehicles remain the most popular. Using data collected from our survey, a multinomial logit model is used to determine individual choices. We find that improving individuals' confidence in air pollution recommendations would be a good way to lead them to choose low-emission rather than high-emission means of transport. Moreover, these estimates also indicate that individuals who attach great importance to comfort are less likely to choose low-emission vehicles than those who value price above other factors. Individual interest can therefore prevail over collective interest, thus verifying the theory of the tragedy of the commons. Different policies (taxes, subsidies, or standard) to encourage people to adopt low-emission vehicles are then tested.
\end{abstract}

Keywords: Air Pollution; Information Campaign; Means of Transport; Tax-Subsidy-Standard; Travellers' Willingness to Pay.

${ }^{*}$ Economie Publique, AgroParisTech, INRA, Université Paris-Saclay, 78850 Thiverval-Grignon, France. Email: caroline.orset@agroparistech.fr. We thank Audrey Haubert, Amandine Menu, the MS ALISEE as well as the audience of the EAERE (2017) and FAERE (2017) for helpful comments and discussions. The views expressed in this article are the sole responsibility of the author and do not necessarily reflect those of its institution. The traditional disclaimer applies. We declare that we have no relevant or material financial interests that relate to the research described in this paper. 


\section{Introduction}

Many actions have been conducted in France to reduce the negative impact of means of transport, such as taxis or diesel vehicles, on air quality. These actions were aimed at encouraging people to use low-emission vehicles, in particular public transport and electric vehicles. Actually, many studies about the adverse effects of air pollution on health have been conducted. Douglas et al (1993) and Krewski et al (2004) found a consistent and statistically significant association between long-term exposure to fine particles with a diameter of $2.5 \mu m\left(P M_{2.5}\right)$ coming from fossil fuels in vehicles and the risk of mortality. Using the fifty-one cities from the American Cancer Society study, Pope et al (2009) reported that wide reductions in $P M_{2.5}$ concentration between 1980 and 2000 were strongly associated with an increase in life expectancy. In 2015, according to a French Senate committee, once the cost of all measures to fight air pollution has been deducted, the net health benefit for France of combating air pollution would be over 11 billion $€$ per year.

Moreover, air pollutants have also a negative impact on the environment. ${ }^{1}$ When fossil fuels are burned, it may create acid rain, which damages trees, buildings and makes the water unsuitable for wildlife. In addition, vehicles contribute to eutrophication, which stimulates blooms of algae and causes fish death and loss of plant and animal diversity. Air pollution from high-emission vehicles also increases haze. Air pollution can also damage crops and trees in reducing growth and survivability of tree seedlings and increasing plant susceptibility to disease. In addition, air pollution is responsible for greenhouse gases, which is a cause of global climate change. In 2015, the French Senate committee estimates the cost of air pollution in France to more than 100 billion $€$ per year.

So why do the French continue to use high-emission vehicles? Are they aware of the negative impact of air pollution on health and the environment? How to lead them to use low-emission vehicles? We built a questionnaire in which we informed respondents about these negative impacts. We consider two groups of respondents that receive two different questionnaires. The questionnaires only differ by the information order received by the respondents. Group 1 first receives information on the negative impact on health and then on the environment of air pollution, while Group 2 first receives information on the negative impact on the environment and then on health. In order to characterize the respondents' preferences for each means of transport, we use the Willingness To Pay method (WTP). Policy-makers are faced with difficult choices when implementing air pollution reduction measures. Understanding people's preferences for these measures allows policy-makers to choose the best health and environmental policies.

Our approach relies on two building blocks. First, our paper is linked to the literature that examines the interaction between the WTP and information acquisition. The WTP approach is a stated preference method. Kroes and Sheldon (1988) and Louviere et al (2000) present and develop the use of this method in diverse fields. This method has been notably used for estimating the individual preferences for means of transport (Baidoo and Nyarko, 2015, for a study in Accra central (Republic of Ghana); Hensher, 1994, for a review on the application

\footnotetext{
${ }^{1}$ See the US Environmental Protection Agency (EPA) for more details.
} 
of stated preference models in the transportation market; Petrik et al, 2016, for a study in Portugal; Wardman, 1988, for a study in the United Kingdom). Moreover, the WTP approach has also been used in air pollution issues. Kotchena et al (2013) have studied the WTP for climate change policies in the United States, Suna et al (2016) and Wanga et al (2016) have focused on the WTP for smog mitigation in China. Our paper contributes to this literature by investigating the WTP for four means of transport (low-emission vehicles: public transport and rented electric vehicle, and high-emission vehicles: taxi and personal vehicle) in France. We find that people have a strong preference for personal vehicles, which are one of the highemission means of transport. We introduce the precise impact of information on the travellers' WTP for the different means of transport. We then conduct an analysis to elicit the WTP for different means of transport with increasing levels of information on the negative impact of air pollution on health and the environment. We observe that information matters but the order of information does not. Indeed, the information caused changes both of the WTP of travellers and their choices. However, the use of high-emission vehicles has not diminished and the personal vehicle is still the preferred mean of transport. Using data collected from our survey, a multinomial logit model was used to determine individual choices. We observe that improving travellers' confidence in air pollution recommendations would be a good way to lead them to choose low-emission rather than high-emission means of transport. Moreover, these estimates indicate that travellers who attach great importance to comfort are less likely necessarily to choose low-emission vehicles than those who value price. Individual interest can therefore prevail over the collective interest, thus verifying the theory of the tragedy of the commons. $^{2}$

Furthermore, we contribute to economics literature on the reduction of air pollution. There is a consensus on the harmful consequences on health and the environment of air pollution due to high-emission vehicles. We then test health and environmental policies: an information campaign on the consequences on health and the environment of air pollution, a tax policy in which high-emission vehicles are taxed, a subsidy policy in which low-emission vehicles are subsidised, and finally, a standard under which high-emission vehicles are forbidden. We also analyse combined policies (tax and subsidy, information campaign and the other tools, standard and subsidy). Some works have analysed the impact of air pollution policies on the structural changes at sectorial level and on energy use (Bollena and Brink, 2014; Naqvi and Zwickl, 2017). Others consider that the volume of pollution produced by an automobile is determined by drivers' behaviour vis--vis three criteria (vehicle selection, kilometres driven, and on-road fuel economy) and they study the optimal policies which could change the driver's behaviour (Montag, 2015). Agostinia and Jimnez (2015) have focused on the gasoline tax as the best instrument of climate policy. Nevertheless, none of these works has studied the impact of health and environmental policies on travellers' behaviour concerning their choice of means of

\footnotetext{
${ }^{2}$ The tragedy of the commons describes a situation in a shared resource system where individual users acting independently for their own benefit behave in a way that is contrary to the common good of all users by depleting or degrading that resource through their collective action. In our study, the common resource is the air, which is a shared resource, and the degradation is due to the pollution created by high-emission transports.
} 
transport. We find that choosing between these health and environmental policies will depend on regulator's priorities. However, two of these policies seem to be good alternatives, namely subsidising low-emission vehicles with or without information campaign.

The paper is organized as follows. Section 2 details the study. Section 3 presents the results with a descriptive analysis and the determinants of travellers' WTP. Section 4 shows the welfare analysis, the determinants of travellers' choices and regulatory advice. Finally, section 5 concludes.

\section{The study}

According to Avem, ${ }^{3}$ pollution related to transport has increased by over $30 \%$ in 20 years, the main cause being the increase in vehicle traffic. Indeed, urban congestion contributes to $75 \%$ of photochemical pollution and $40 \%$ of acid deposition. We then propose to analyse French travellers' willingness to pay in order to reduce air pollution related to transport.

\section{$2.1 \quad$ Target respondents}

During February 2015, we conducted the study through Marketest. ${ }^{4}$ We asked Marketest to create two groups of respondents. Each group was selected by using the quota method, i.e., the same proportions of gender, age and socioeconomic status (income and occupation) criteria in the group of respondents as in the census report of the French population by the Institut national de la statistique et des études conomiques (INSEE) in 2013. We had prepared specifically for this study two questionnaires, one for each group, to be posted online. The two questionnaires only differed by the order in the information received by the respondents. Group 1 first received information on the negative impact of air pollution, first on health and then on the environment. Group 2, on the other hand, first received information on the negative impact on the environment and then on health. Group 1 target respondents consists of 177 French people aged between 20 and 65. Group 2 target respondents are 165 French people aged between 20 and 80 .

Table 1 presents the socioeconomic characteristics (gender, age, income, and occupation) of the respondents. Differences between the two groups and INSEE data are tested using the Pearson chi-squared test. A P-value (against the null hypothesis of no difference) of less than $5 \%$ is considered significant. The results in the last three columns of Table 1 suggest that the three groups are not significantly different.

\footnotetext{
${ }^{3}$ See: http://www.avem.fr/index.php?page=pollution

${ }^{4}$ For more details on Marketest see: http://www.marketest.co.uk/.
} 


\begin{tabular}{|c|c|c|c|c|c|c|}
\hline Description & Group $1(\%)$ & Group $2(\%)$ & INSEE $(\%)$ & $\begin{array}{l}\text { Chi2 test P-value } \\
\text { between Group } 1 \\
\text { and Group } 2\end{array}$ & $\begin{array}{l}\text { Chi2 test P-value } \\
\text { between Group } 1 \\
\text { and INSEE }\end{array}$ & $\begin{array}{c}\text { Chi2 test P-value } \\
\text { between Group } 2 \\
\text { and INSEE }\end{array}$ \\
\hline \multicolumn{7}{|l|}{ Gender } \\
\hline Female & 50.3 & 53.3 & 51.5 & 0.58 & 0.83 & 0.74 \\
\hline Male & 49.7 & 46.7 & 48.5 & & & \\
\hline \multicolumn{7}{|l|}{ Age } \\
\hline$[20-24]$ & 13.6 & 17.0 & 16.0 & 0.28 & 0.68 & 0.14 \\
\hline$[25-59]$ & 75.7 & 67.9 & 75.8 & & & \\
\hline $60 \leq$ & 10.7 & 15.1 & 8.1 & & & \\
\hline \multicolumn{7}{|l|}{ Monthly net income of the household $(€)$} \\
\hline$<1000$ & 11.9 & 12.1 & 10.0 & 0.75 & 0.63 & 0.10 \\
\hline$[1000-1500)$ & 20.9 & 13.9 & 20.0 & & & \\
\hline$[1500-2500)$ & 23.1 & 30.3 & 20.0 & & & \\
\hline $2500 \leq$ & 44.1 & 43.7 & 50.0 & & & \\
\hline \multicolumn{7}{|l|}{ Professional groups } \\
\hline Farmer & 0.6 & 0 & 1.0 & 0.19 & 0.24 & 0.07 \\
\hline Craftsman & 3.4 & 3.6 & 3.0 & & & \\
\hline Self-employed and executive & 28.8 & 21.8 & 22.6 & & & \\
\hline Employee and worker & 33.9 & 35.2 & 29.2 & & & \\
\hline Retired person, unemployed person, and homemaker & 33.3 & 39.4 & 44.2 & & & \\
\hline
\end{tabular}

Table 1: Socioeconomic characteristics of respondents. 177 respondents (Group 1) and 165 respondents (Group 2).

Through informational questions on the respondents, we understand that for $41.8 \%$ of Group 1 respondents and $34.6 \%$ of Group 2 respondents, price is the first criterion for selecting their means of transport. $29.4 \%$ of Group 1 respondents and $36.9 \%$ of Group 2 respondents take into account primarily travel time, and $28.8 \%$ of Group 1 respondents and $28.5 \%$ of Group 2 respondents the well-being during the ride. Only $33.3 \%$ of Group 1 respondents and $33.9 \%$ of Group 2 respondents are directly or indirectly (through family) affected by air pollution health issues such as asthma, respiratory disorders or allergies. Finally, 56.5\% of Group 1 respondents and $65.5 \%$ of Group 2 respondents take into account the recommendations when a pollution peak is announced. Therefore, the majority of respondents in both groups trusts the air pollution recommendations.

\subsection{Means of transport}

We have chosen to focus on the journey from the center of Paris (the Châtelet Paris Metro station) to the Paris Charles de Gaulle Airport (around $33 \mathrm{~km}$ (20 miles) using the $A_{1}$ Highway by vehicle, public transport also follows this route, with a 30-minute travel time for each means of transport). This journey is used every day for leisure and business trips. Therefore, even French people who do not live in Paris can have made this trip. Moreover, the $A_{1}$ Highway 
between Paris and Charles de Gaulle Airport, peculiarly around the suburb of Saint-Denis, is one of the most polluted road sections in France. Table 2 shows that standards are often exceeded on this particular road section.

\begin{tabular}{|l|c|c|c|}
\hline Polluting & Limit Value & Target Value & Quality Goal \\
\hline $\mathrm{PM}_{10}$ & Exceeded & & Exceeded \\
\hline $\mathrm{PM}_{2.5}$ & Exceeded & Exceeded & Exceeded \\
\hline $\mathrm{NO}_{\mathrm{x}}$ & Complied with & & \\
\hline $\mathrm{CO}$ & Complied with & & \\
\hline
\end{tabular}

Table 2: Situation of different pollutants regulated in relation to air quality standards on $A_{1}$ Highway in 2015. From Airparif (2016).

We propose to respondents four means of transport for the journey: a taxi (TAXI), a personal vehicle (PV), a rented electric vehicle (REV), and public transport (PT) (bus, subways...). ${ }^{5}$ These means of transport emit very different levels of pollutants. Table 3 sums up for each transport, the ride cost, the level of vehicle on dioxide $\left(\mathrm{CO}_{2}\right)$, the level of vehicle on monoxide $(C O)$, the level of nitrogen oxide $\left(N O_{x}\right)$ which is the sum of nitrogen monoxide $(N O)$ and nitrogen dioxide $\left(\mathrm{NO}_{2}\right)$, and the level of particles $\left(P M_{10}\right.$ and $\left.P M_{2.5}\right)$ for the total journey. ${ }^{6}$

\footnotetext{
${ }^{5}$ These means of transport were and are still the only ones proposed to make this journey. A taxi corresponds to a Parisian taxi or to a privately driven transport vehicle.

${ }^{6}$ The price for a ride for each mean of transport is the market price in February 2015. For the taxi: http://www.parisaeroport.fr/en/passengers/access/paris-charles-de-gaulle/taxi/paris-cdg-taxi; For the personal vehicle: from ViaMichelin (which considers fuel and highway fees); For the rented electric vehicle: from Autolib, https://www.autolib.eu/fr/ ; for the public transport: from RATP. Moreover, we have chosen to present these pollutants because they are the ones selected by VEHICLE LABELLING ADEME, which imposes no-claims bonus to vehicles. For Public transport: $\mathrm{CO}_{2}$ : RATP-GETTING AROUND-TIMETABLE, $N O_{x}$ and Particles: Airparif (http://www.airparif.fr/calculateur-emissions/), and CO: CITEPA (http://www.citepa.org/fr/airetclimat/analyse-sectorielle/transports); for Taxi, Personal Vehicle, Rented Electric Vehicle: $\mathrm{CO}_{2}, \mathrm{CO}_{\text {: VEHI- }}$ CLE LABELLING ADEME (mean of diesel vehicles for Taxi and Personal Vehicle, and mean of electric vehicles for rented electric vehicle), $N O_{x}$ : Airparif (http://www.airparif.fr/calculateur-emissions/) and Particles: average between data from Airparif (http://www.airparif.fr/calculateur-emissions/) and Timmers and Achten (2016) for a weight at $1120 \mathrm{~kg}$ for a rented electric vehicle and $1600 \mathrm{~kg}$ for taxi and personal vehicle.
} 


\begin{tabular}{|l|c|c|c|c|c|}
\hline Means of Transport & Cost $(€)$ & $\mathrm{CO}_{2}(\mathrm{~g})$ & $\mathrm{CO}(\mathrm{g})$ & NOx $(\mathrm{g})$ & Particles $(\mathrm{g})$ \\
\hline Taxi & 50 & 5620 & 9.874 & 19.4 & 2.8 \\
\hline Personal Vehicle & 3.7 & 5620 & 9.874 & 19.4 & 2.8 \\
\hline Rented Electric Vehicle & 13.5 & 0 & 0 & 0 & 1.4 \\
\hline Public Transport & 10 & 108 & 0.047 & 0 & 0.3 \\
\hline
\end{tabular}

Table 3: Costs and levels of pollution for each kind of transports and for the total journey.

According to the World Health Organization (WHO), $C O$ can cause poisoning, resulting in headaches and dizziness or even coma or death from prolonged exposure. The limit value from a health protection perspective is $10,000 \mu \mathrm{g} / \mathrm{m}^{3}$ on average over 8 hours. Its oxidation results in the formation of $\mathrm{CO}_{2}$, which is a greenhouse gaz. $\mathrm{CO}_{2}$ emissions affect climate in the short and long terms. From a certain concentration in the air, the $\mathrm{CO}_{2}$ is dangerous or fatal. The exposure limit is $3 \%$ over a period of 15 minutes. At $25 \% \mathrm{CO}_{2}$ in air, respiratory arrests can occur, resulting in death. $\mathrm{NO}_{x}$ does not have direct health effects. However, $\mathrm{NO}_{2}$ can cause respiratory tract inflammation, an increase of bronchitis symptoms and reduced lung function. Moreover, $N O_{x}$ contributes to the phenomenon of acid rain that depletes the environment (soil and vegetation). The particles $\left(P M_{10}\right.$ and $\left.P M_{2.5}\right)$ have adverse effects on health. Chronic exposure helps increase the risk of contracting cardiovascular and respiratory diseases, and lung cancers. The annual limit value to protect health are $40 \mu \mathrm{g} / \mathrm{m}^{3}$ annual average for $P M_{10}$ and $25 \mu \mathrm{g} / \mathrm{m}^{3}$ for $P M_{2.5}$. Through the hugely dominant effect of particles is on human health, they also have a harmful effect on the environment. They degrade buildings. They have an impact on climate by absorption and scattering of solar radiation as well as the formation of clouds.

Therefore, it seems important to propose the use of low-emission means of transport because they have the least negative impacts on health and the environment. According to Table 3, we see that rented electric vehicle and public transport are low-emission means of transport while taxi and personal vehicle are high-emission means of transport. Note that we have informed the respondents that we consider diesel taxis and diesel personal vehicles. Actually, in Paris, diesel taxis represent $99.9 \%$ of the taxi fleet and diesel personal vehicles, $62.2 \%$ of the personal vehicle fleet. ${ }^{7}$

\footnotetext{
${ }^{7}$ http://www.paris.fr/taxis\#subventions-taxis-propres 3 and http://www.ccfa.fr/IMG/pdf/cpparcfrance_2016ok.pdf.
} 


\subsection{Experimental design and information revealed}

In each questionnaire, successive messages emphasizing health and environmental impacts of air pollution are delivered to survey respondents. Means of transport are a source of air pollutants. According to the Paris air pollution measurement agency Airparif, ${ }^{8}$ the transport sector represents $24.3 \%$ of the $\mathrm{CO}_{2}$ emissions, $57 \%$ of the $N O_{x}$ emissions, $32 \%$ of the $P M_{10}$ emissions, $38 \%$ of the $P M_{2.5}$ emissions in Ille-de-France (Greater Paris administrative area, in which the journey from the center of Paris (Châtelet Metro station) to the Paris Charles de Gaulle Airport is realized).

We want to raise respondents' awareness about health and environmental issues related to their decisions on means of transport. In order to characterize their preferences for each means of transport, we use the Willingness To Pay method (WTP). WTP is elicited after each message with the following question: How much would you be willing to pay as a maximum fare for a trip from the center of Paris (Châtelet Metro station) to the Paris Charles de Gaulle Airport by taxi, public transport, rented electric vehicle and personal vehicle? The study is divided into several stages as described in Figure $1 .^{9}$

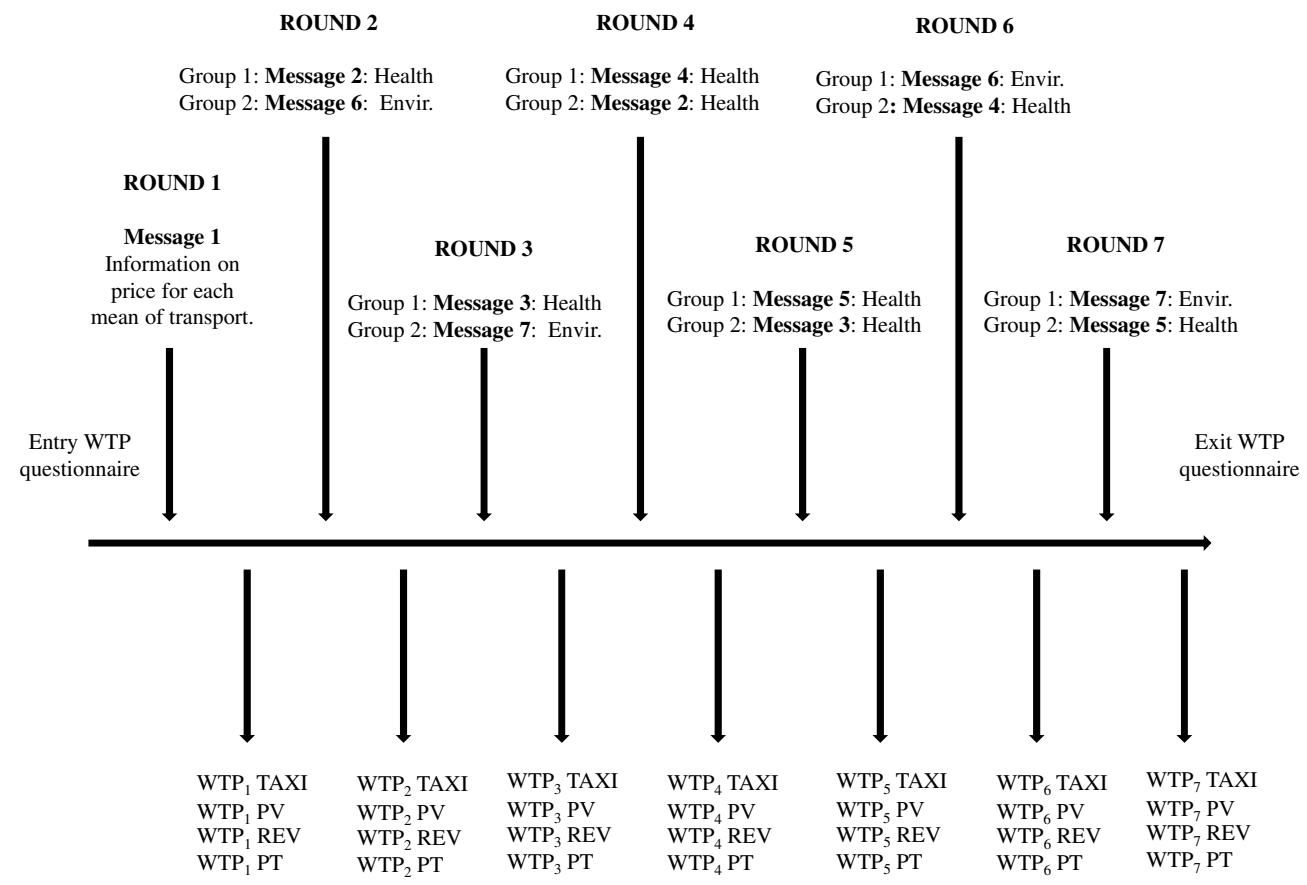

Figure 1: Questionnaire design.

\footnotetext{
${ }^{8}$ For more details see: http://www.airparif.asso.fr/etat-air/air-et-climat-quelques-chiffres.

${ }^{9}$ Messages are given in Appendix.
} 
The sequence of information revealed differs between both groups. Group 1 first received information on the negative impact of air pollution on health and then on the environment, while Group 2 first received information on the negative impact on the environment and then on health. Each questionnaire was given to respondents as follows. First, a text helps respondents understand the purpose of the study: This study is conducted by economists working in academia without any link to government. This survey focuses on different means of transport that may be used to make the journey from the center of Paris (Châtelet Metro station) and Roissy Charles De Gaulle airport. The travel time is 30 minutes whatever means of transport you choose. We do not give more information to limit framing effect and anchoring bias. ${ }^{10}$ Then, respondents fill a questionnaire with informational and socio-demographic characteristics questions. We needed this information in order to analyse the WTP and choices determinants. Finally, based on different types of information revealed to respondents, seven messages of WTP elicitation are successively determined.

We have decided to divide the set of information into air pollution impact on health and air pollution impact on the environment. Table 4 describes the messages and the respondents' behaviours expected.

\begin{tabular}{|c|c|c|c|c|}
\hline Message & Category & Description & Behaviour expected & Comment \\
\hline Message 1 & & $\begin{array}{l}\text { Prices of a ride on each means } \\
\text { of transport. }\end{array}$ & & $\begin{array}{l}\text { Cheap talk as Lusk (2003) suggests limiting } \\
\text { hypothetical bias. The hypothetical bias refers } \\
\text { to the fact that the situation presented is } \\
\text { described as hypothetical, and therefore the } \\
\text { WTP may differ from the actual WTP. }\end{array}$ \\
\hline Message 2 & Health & $\begin{array}{l}\text { Consequences of air pollution on the } \\
\text { number of premature deaths (more than } 2 \\
\text { million) each year worldwide. }\end{array}$ & $\begin{array}{l}\text { Decrease of WTP for taxi and } \\
\text { personal vehicle. Increase of } \\
\text { WTP for public transport and } \\
\text { rented electric vehicle. }\end{array}$ & Focus on global pollution. \\
\hline Message 3 & Health & $\begin{array}{l}\text { Consequences of air pollution on the } \\
\text { number of premature deaths ( } 400,000 \text { in } \\
\text { Europe, } 42,000 \text { in France, } 1,400 \text { in Paris }) \\
\text { each year. }\end{array}$ & $\begin{array}{l}\text { Decrease of WTP for taxi and } \\
\text { personal vehicle. Increase of } \\
\text { WTP for public transport and } \\
\text { rented electric vehicle. }\end{array}$ & Focus on local pollution. \\
\hline Message 4 & Health & $\begin{array}{l}\text { Data on actual and recommended level of } \\
\text { fine particules and on the impact of fine } \\
\text { particles on the life expectancy of } \\
\text { parisians and persons from the suburbs. }\end{array}$ & $\begin{array}{l}\text { Decrease of WTP for taxi and } \\
\text { personal vehicle. Increase of } \\
\text { WTP for public transport and } \\
\text { rented electric vehicle.. }\end{array}$ & $\begin{array}{l}\text { More technical focus. See whether people } \\
\text { are sensitive to data. }\end{array}$ \\
\hline Message 5 & Health & Health costs of air pollution in France. & $\begin{array}{l}\text { Decrease of WTP for taxi and } \\
\text { personal vehicle. Increase of } \\
\text { WTP for public transport and } \\
\text { rented electric vehicle. }\end{array}$ & $\begin{array}{l}\text { Economics focus. See whether people are } \\
\text { sensitive to the health costs of air pollution. }\end{array}$ \\
\hline Message 6 & Environment & Air pollution impact on buildings. & $\begin{array}{l}\text { Decrease of WTP for taxi and } \\
\text { personal vehicle. Increase of } \\
\text { WTP for public transport and } \\
\text { rented electric vehicle. }\end{array}$ & Urban preservation focus. \\
\hline Message 7 & Environment & $\begin{array}{l}\text { Consequences of air pollution on climate } \\
\text { change and ecosystem. }\end{array}$ & $\begin{array}{l}\text { Decrease of WTP for taxi and } \\
\text { personal vehicle. Increase of } \\
\text { WTP for public transport and } \\
\text { rented electric vehicle. }\end{array}$ & Ecological focus. \\
\hline
\end{tabular}

Table 4: Description of the messages and respondents' behaviour expected.

\footnotetext{
${ }^{10}$ Framing effect is the tendency to be influenced by the way a problem is presented. The anchoring bias is the tendency unduly to use information as a reference.
} 


\section{Results}

\subsection{Descriptive analysis}

Figures 2 and 3 present, with boxplots, the distributions of the WTP for each means of transport and the information (message) provided for Group 1 and for Group 2, respectively. For each boxplot, we indicate the means with a cross and the median with a line.



Figure 2: Distribution of the Willingness-To-Pay for each mean of transport in euro for Group 1.

We understand that the dispersion for the WTP for personal vehicles and public transport is not affected by the messages while that of rented electric vehicles and taxis tend to increase. Therefore, the succession of messages seems to create more divergence between the respondents' WTP for these two means of transport.

We then observe that Messages 3, 6 and 7 have on average an unexpected consequence on the respondents' WTP for taxi, public transport and rented electric vehicle. Indeed, Message 3 decreases on average the respondents' WTP for public transport and rented electric vehicles. 
Moreover, Message 6 decreases on average the respondents' WTP for rented electric vehicles while Message 7 increases the respondents' WTP for taxis. On the other hand, only Message 6 has the expected consequence on the respondents' WTP for personal vehicles, which is an average decrease respondents' WTP for their personal vehicle. Therefore, the expected goal of the different messages on respondents' preferences concerning personal vehicles is on average not reached.

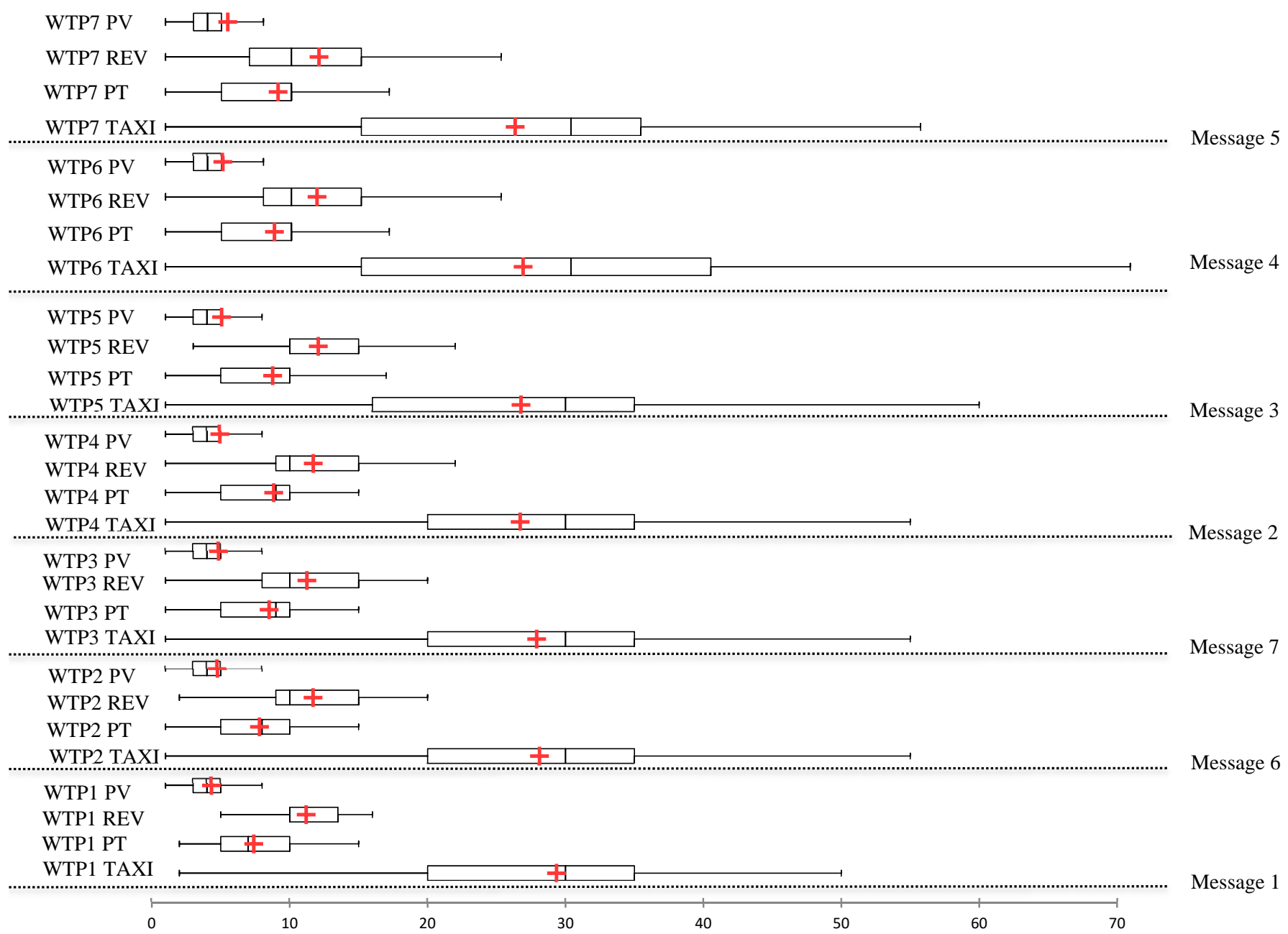

Figure 3: Distribution of the Willingness-To-Pay for each mean of transport in euro for Group 2.

We understand that the dispersion for the WTP for personal vehicles and for public transport is not affected by the messages while that of rented electric vehicles and taxis tend to increase, just as for Group 1.

We then see that Messages 3, 4 and 7 have on average an unexpected consequence on the respondents' WTP for taxi, public transport and rented electric vehicle. However, no message achieves the expected objective with regard to the preferences of respondents on average for their personal vehicle. 
Therefore, for both groups, it appears that the information campaign messages fail to decrease respondents' preferences for their personal vehicle. They even lead to an increase. In addition, if we focus on all other means of transport except personal vehicles, we note that Messages 3, 4, 6 and 7 may not achieve the expected goal for respondent preferences. Only Messages 2 and 5 have the expected effects.

We now test, for each group of respondents, the significance of the average WTP differences linked to the information revelation with the Wilcoxon test for paired samples. ${ }^{11}$ We consider the significance of the differences at the $5 \%$ level. The test is made as follows: we compare the average WTP before and after each message. This allows us to measure the impact of information revelation on the average respondents' WTP for a given means of transport. Table 5 sums up the results. We note in the table 'Decrease' when the difference significantly decreases, and 'Increase' when the difference significantly increases from a message to another.

\begin{tabular}{|c|c|c|c|c|}
\hline \multirow[b]{2}{*}{ Between } & \multicolumn{2}{|c|}{ Taxi } & \multicolumn{2}{|c|}{$\mathrm{PV}$} \\
\hline & Group 1 & Group 2 & Group 1 & Group 2 \\
\hline Messages 1 and 2 & Decrease & Decrease & Increase & \\
\hline Messages 2 and 3 & Decrease & & & \\
\hline \multicolumn{5}{|l|}{ Messages 3 and 4} \\
\hline Messages 4 and 5 & & & Increase & \\
\hline Messages 5 and 6 & & & Decrease & \\
\hline \multirow[t]{2}{*}{ Messages 6 and 7} & & & Increase & \\
\hline & \multicolumn{2}{|c|}{ REV } & \multicolumn{2}{|c|}{ PT } \\
\hline Between & Group 1 & Group 2 & Group 1 & Group 2 \\
\hline Messages 1 and 2 & & Increase & Increase & \\
\hline Messages 2 and 3 & Decrease & & & \\
\hline Messages 3 and 4 & & & & \\
\hline Messages 4 and 5 & & & & \\
\hline Messages 5 and 6 & & & Increase & \\
\hline Messages 6 and 7 & & & & Increase \\
\hline
\end{tabular}

Table 5: Results from the Wilcoxon test.

Table 5 strengthens the previous results. Moreover, we note that message 4 does not affect any of the groups significantly. Table 5 also shows that respondents from both groups are not significantly affected by the same messages. However, when they are affected, it is in the same way.

Finally, we observe that $17.5 \%$ of Group 1 respondents and $22.4 \%$ of Group 2 respondents have the same WTP before and after receiving all the messages. Therefore, informing these respondents on the damages on health and the environment of air pollution does not change their preferences for a means of transport. In fact, either individuals prefer to ignore information even if there is potential damage to health and the environment because this behaviour maximizes their own well-being (Chemarin and Orset, 2011), or they already have information about it.

\footnotetext{
${ }^{11}$ The Wilcoxon test is a nonparametric average comparison test of two independent or matched samples. For more details, see Chapter 7 of Tanizaki (2004).
} 


\subsection{Econometric estimations: Willingness-To-Pay}

We now investigate the determinants of WTP through estimations. We use a Random effects panel model on pooled data. ${ }^{12}$ This model allows us to analyse the effect of each determinant on the dependent variable, here travellers' WTP. The random effects model can be written as

$$
y_{i t}=\alpha+x_{i t}^{\prime} \beta+z_{i}^{\prime} \gamma+c_{i}+u_{i t},
$$

for $t=1 \ldots T$ and $i=1, \ldots, N$ with $N=2394$ observations and $T=7$ time periods, where $y_{i t}$ is the dependent variable observed for individual $i$ at time $t$, that is the individual $i$ 's WTP for one of the mean of transport at time is a 8-dimensional row vector of time-varying explanatory variables; we have dummies for the type of information Health or Environment (Information on Environment: 0 for no and 1 for yes), for the order of the received message (Information on Environment received first: 0 for no and 1 for yes), for available information at the moment of the WTP elicitations (Message X: 0 for no and 1 for yes); $z_{i}$ is a 18-dimensional row vector of timeinvariant explanatory variables excluding the constant, that is: having one's health impacted by air pollution (asthma, respiratory disorders, allergies), the individual importance attached to the air pollution index, the individual's confidence on air pollution recommendations, gender, income, age, professional groups, individual's localisation in the Île-de-France area, and their criteria of selection between price and comfort. Having one's health impacted by air pollution is a dummy variable ( 0 for no and 1 for yes); Individual importance attached to air pollution is divided into four variables (Importance attached to air pollution index-0: none; Importance attached to air pollution index-1: weak ; Importance attached to air pollution index-2: high; Importance attached to air pollution index-3: very high), the individual's confidence on air pollution recommendations is divided into four variables (Confidence on recommendation-0: none; Confidence on recommendation-1: weak ; Confidence on recommendation-2: high; Confidence on recommendation-3: very high). Age is a quantitative variable and gender is a dummy variable ( 1 for woman and 0 for man). We have divided income into four variables (Income-0: $1000_{i}$; Income-1: [1000,1500) ; Income-2: [1500,2500) ; Income-3: 2500 $\leq$ ), professional groups into five variables (SPC-0: Farmer ; SCP-1: Craftsman ; SCP-2: Self-employed and executive ; SCP-3: Employee and worker ; SCP-4: Retired person, unemployed person and homemaker), an individual's localisation in the Île-de-France area (IDF) is a dummy variable ( 1 for yes and 0 for no), and the individual's criteria for selecting between price and comfort is a dummy variable ( 1 for Comfort and 0 for Price); $\alpha$ is the intercept; $\beta$ is a 8 -dimensional column vector of parameters; $\gamma$ is a 18-dimensional column vector of parameters; $c_{i}$ is an individual-specific effect and $u_{i t}$ is an idiosyncratic error term. We note that with a random effects model, the individual-specific effect is a random variable, which is uncorrelated with the explanatory variables. In the model, Importance attached to the air pollution index-0, Confidence on recommendation- 0 , Income-0

\footnotetext{
${ }^{12}$ According to the Breusch-Pagan test, which tests the null hypothesis that the pooled OLS estimator is adequate against the random effects alternative, we obtain that the random effects model is favourable. Then, we make the Hausman test, which tests the null hypothesis that the random effects model is preferable to fixed effect model. We obtain that the test counts against the fixed effects model and in favour of random effects. See Chapter 11 of Greene (2017).
} 
and SCP-0 are reference modalities. Table 6 presents the estimations results. ${ }^{13}$

\begin{tabular}{|c|c|c|c|c|}
\hline $\begin{array}{l}\text { Endogenous variable } \\
\text { Model: Random effects model }\end{array}$ & $\begin{array}{l}\text { Pooled Willingness } \\
\text { To Pay for Taxi in } €\end{array}$ & \begin{tabular}{|c|} 
Pooled Willingness \\
To Pay for Personal \\
Vehicle in $€$
\end{tabular} & $\begin{array}{l}\text { Pooled Willingness } \\
\text { To Pay for Rented } \\
\text { Electric Vehicle in } €\end{array}$ & $\begin{array}{l}\text { Pooled Willingness To } \\
\text { Pay for Public } \\
\text { Transport in } € \\
\end{array}$ \\
\hline Constant & 26.551** (13.279) & $2.368(4.211)$ & $14.324(5.633)$ & 7.511* (4.174) \\
\hline Information on Environment (1/0) & $\mathbf{- 2 . 1 8 5} * * *(0.667)$ & $0.104(0.215)$ & $-0.428(0.325)$ & $-0.041(0.265)$ \\
\hline Message 2 & $\mathbf{- 3 . 0 5 9} * * *(0.590)$ & $0.293(0.190)$ & $0.248(0.288)$ & $\mathbf{0 . 6 0 7 * * *}(0.234)$ \\
\hline Message 3 & $\mathbf{- 0 . 8 4 5 * ( 0 . 4 6 9 )}$ & $0.129(0.151)$ & $-0.119(0.229)$ & $-0.127(0.186)$ \\
\hline Having its health impacted by air pollution $(1 / 0)$ & $\mathbf{2 . 7 3 1} *(1.537)$ & $-0.457(0.487)$ & $-0.613(0.652)$ & $0.394(0.483)$ \\
\hline Importance attached to the air pollution index-2 (-0) & $0.201(2.252)$ & $0.285(0.714)$ & $\mathbf{1 . 9 5 3}^{* *}(0.955)$ & $0.749(0.707)$ \\
\hline Importance attached to the air pollution index-3 (-0) & $2.445(1.705)$ & $0.555(0.540)$ & $1.829 * *(0.723)$ & $0.488(0.536)$ \\
\hline Confidence on recommendation-2 (-0) & $0.308(2.347)$ & $0.912(0.744)$ & $-1.302(0.995)$ & $1.100 *(0.737)$ \\
\hline Age & $0.070(0.051)$ & $-0.559(0.454)$ & $-\mathbf{0 . 0 4 9} * *(0.022)$ & $-0.010(0.016)$ \\
\hline Observations & 2.394 & 2.394 & 2.394 & 2.394 \\
\hline $\mathrm{R}^{2}$ & 0.083 & 0.045 & 0.049 & 0.042 \\
\hline Log-likelihood & -9626.102 & -6883.724 & -7640.004 & -6975.327 \\
\hline
\end{tabular}

Table 6: Results from Random effects panel model about pooled WTPs in levels. ${ }^{*} p<0.1 ;{ }^{* *} p<0.05$; ${ }^{* * *} p<0.01$. Standard errors in parentheses.

All the regressions are significant and the $R^{2}$ varies between $4.2 \%$ and $8.3 \%$. We understand that providing information on the environment significantly decreases the WTP for a taxi by $€ 2.18$. In addition, providing Message 2, which is a message on health explaining the consequences of air pollution on deaths worldwide, significantly decreases the WTP for a taxi by $€ 3.06$ while it increases the WTP for public transport by $€ 0.61$. Finally, providing Message 3, which is a message on health explaining the consequences of air pollution on death in Europe, significantly decreases the WTP for a taxi by $€ 0.84$. Therefore, Messages 2 and 3 respond to the goal to decrease travellers' preferences for a taxi, and message 2 does the same for public transport. This strengthens the previous results. These messages showing the number of deaths due to air pollution and its impact on the environment could be given to travellers in order to decrease their preferences for a high-emission means of transport and increase the ones for lowemission. However, as shown in the descriptive part, these messages could also increase the preferences for a personal vehicle. Therefore, the use of these messages must be taken vehicle fully.

\footnotetext{
${ }^{13}$ We only keep in Table 6 the significant results. See in Appendix for the complete table.
} 
Moreover, having one's health impacted by air pollution significantly increases the WTP for the taxi by $€ 2.73$. Respondents who have a high or a very high interest for the air pollution index increase significantly their WTP for the rented electric vehicle by $€ 1.95$ and $€ 1.83$ related to respondents who do not vehicle about the pollution index, respectively. Moreover, travellers who highly believe to air pollution recommendation increase their WTP for public transport by $€ 1.10$ related to those who do not have such confidence. Therefore, giving confidence to respondents would be useful for convincing them to use public transport, which is one of the low-emission means of transport. Finally, the WTP for rented electric vehicle decreases by $€ 0.05$ with age, surely due to a lack of knowledge about the means of electric transport and/or ingrained habits in elderly people.

\section{Welfare and regulation}

In this section, based on elicited WTP for the means of transport, we deduce the individual's choices. We then investigate the welfare impact of various health and environmental policies (information campaign, tax, subsidy, and standard) on these choices. We assume that all means of transport (taxi, public transport, personal vehicle and electric rented vehicle) are available on the market.

\subsection{Demand and supply of means of Transport}

Figure 4 shows the ordered WTP of the set of respondents (Group 1 and Group 2) for the four means of transport before and after information about the consequences on health and environment of the use of means of transport. The cumulative number of respondents (equivalent to one used means of transport per participant) is represented on the $\mathrm{X}$-axis and the ordered WTP (in Euros) corresponding to the cumulative number of respondents is represented on the Y-axis in decreasing order. In each graph, the curves represent travellers' demands for the means of transport before (solid line) and after information (dotted line). ${ }^{14}$ The price paid by travellers for a ride (€50 for taxi, $€ 3.7$ for a personal vehicle, $€ 13.5$ for a rented electric vehicle, and $€ 10$ for public transport), that is the market price, is in a dashed line. We define the traveller surplus for a means of transport as the difference between what travellers are willing to pay for a means of transport relative to its market price. ${ }^{15}$ The four graphs thus allow us to analyse the information impact on the demand, and therefore on the traveller surplus.

\footnotetext{
${ }^{14}$ Note that the WTP in all the curves is ordered, which means that a given number on the X-axis indicates the ranking of WTP related to each curve and not a specific participant.

${ }^{15}$ Here, as we are considering a situation of travel, we will use the term traveller surplus instead of consumer surplus as in the economics literature.
} 

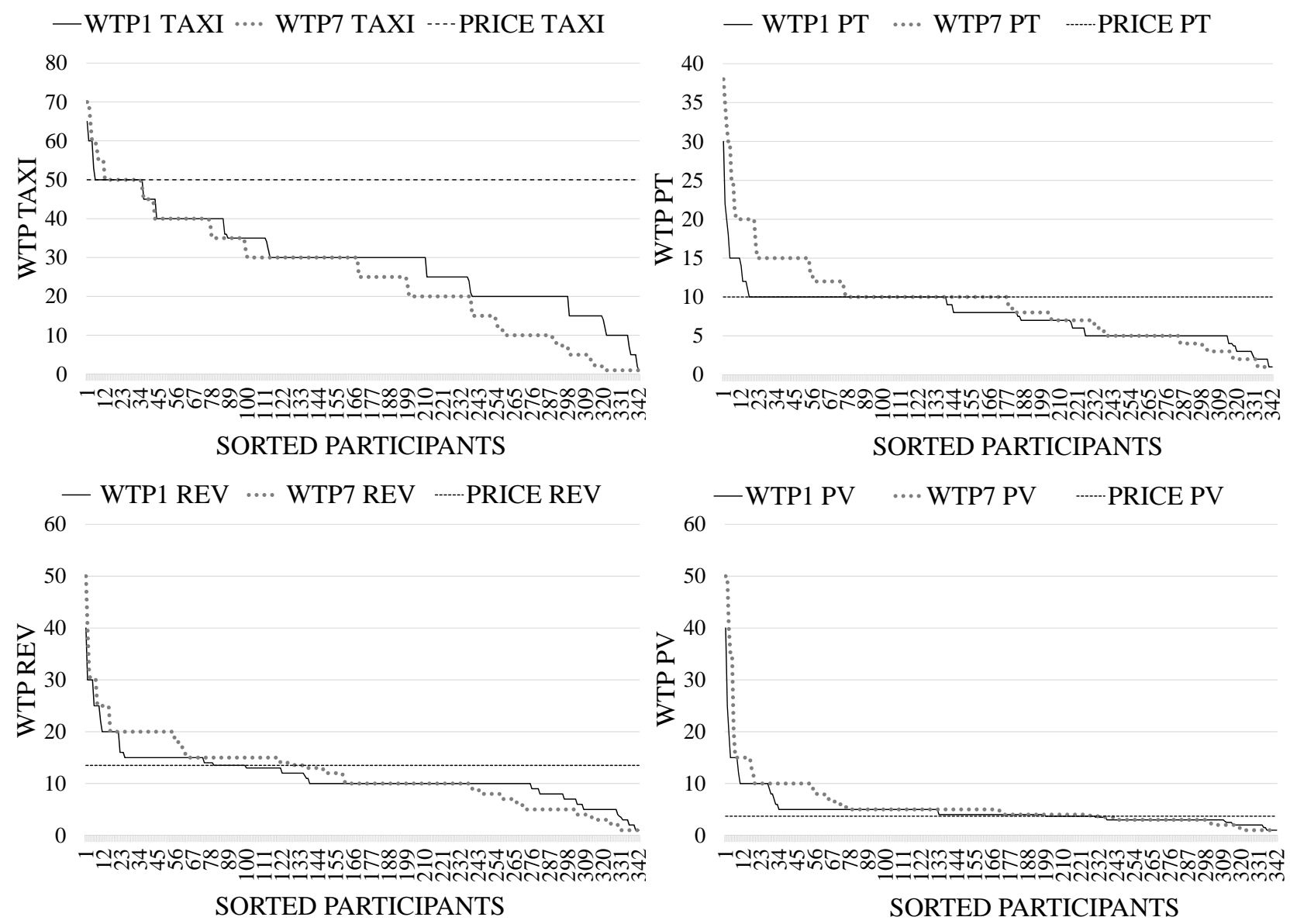

Figure 4: Observed demand functions of the set of 342 respondents (in euro) before (solid line) and after information (dotted line), and the market price (dashed line) for the four means of transport.

The left sides (right sides) of each graph show that, for relatively high-values (low-values) of WTP, the WTPs before information are significantly lower (higher) than the WTPs after information. In all four graphs, it is consistently observed that information leads to a rightward shift in the cumulative distribution function except for low WTP values. Based on the descriptive result, it appears that information about the consequences of means of transport on health and the environment leads to a welfare (surplus) increase for travellers.

Now, we assume that each respondent would choose the means of transport with the highest traveller surplus, which is the largest difference between its WTP and the market price. This choice is inferred because the real choice is not observed in the study, which only elicits WTP. Despite this limitation, this methodology is useful for estimating ex ante individuals' reactions to regulatory instruments. We consider the number of travellers for a means of transport as an equivalent to the number of respondents who decide to use this means of transport for the journey. We introduce the possibility that more than one means of transport can lead to the highest traveller surplus. In this situation, we assume that a traveller chooses these means 
of transport with the same probability. We then obtain an expected number of travellers for each means of transport. For example, if traveller i has their highest traveller surplus for taxi and for public transport, then we consider that the expected number of travellers for taxi is one half, for public transport is one half and it is equal to zero for rented electric vehicles and personal vehicles. Moreover, we consider that if for all the means of transport, the traveller has a negative traveller surplus, that is if their WTP were lower than the market price for all means of transport, then the traveller would not choose anything and the trip would not be made. In this context, we note the traveller's choice as NONE, and we consider that the traveller surplus is equal to zero. ${ }^{16}$ Figure 5 represents, for each group, the expected number of travellers after and before information for all the possible choices (Taxi, PT, REV, PV and NONE) given to respondents.

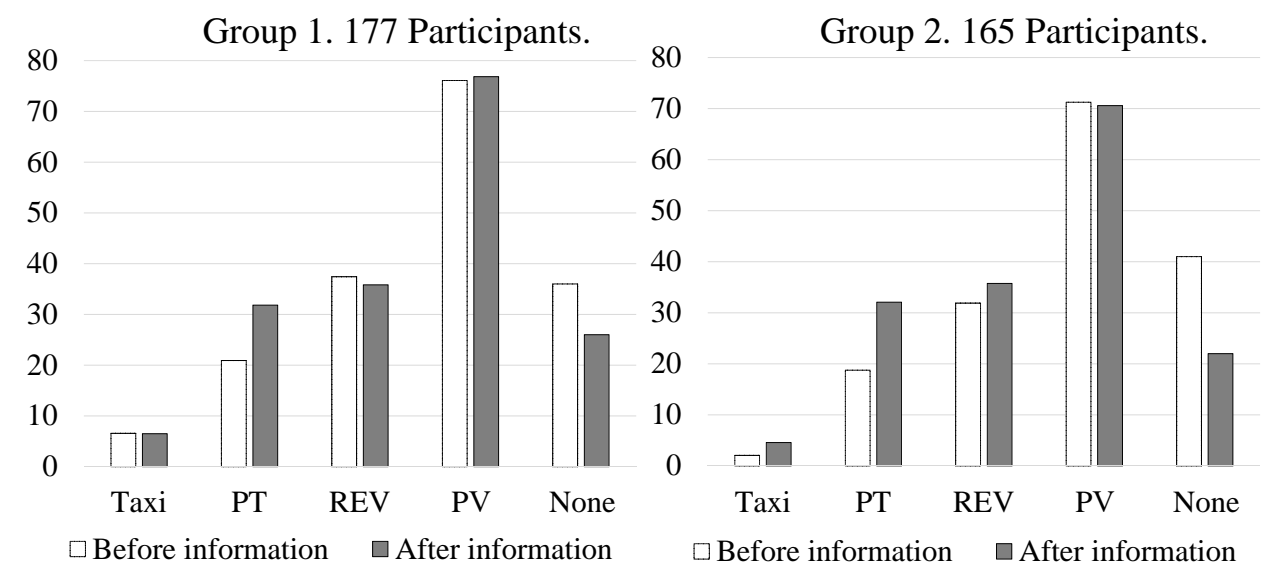

Figure 5: Expected number of travellers over the 177 (Group 1) and 165 (Group 2) respondents for the five possible choices before and after information (Round 1 and Round 7).

We first observe that personal vehicles are the most chosen means of transport. Moreover, we see that information changes the expected number of travellers in the different categories. Using the Mann-Whitney-U test ${ }^{17}$ we investigate whether the two groups of respondents are initially similar, i.e., whether the choices (Taxi, PT, REV, PV and NONE) expressed in the first round are statistically similar between the two groups. The test result suggests no significant difference at the $5 \%$ level. In addition, using the Mann-Whitney-U test, we show that the choices after information are not significantly different between Groups 1 and 2. Therefore,

\footnotetext{
${ }^{16}$ However, for the calculation of the number of travellers, we were careful to differentiate the traveller surplus equal to zero because the price were higher than the WTP and that because the price were equal to the WTP. In the latter case, the traveller may choose the mean of transport.

${ }^{17}$ In statistics, the Mann-Whitney-U test is a nonparametric test that tests the hypothesis that the distribution of data is the same in two groups.
} 
the order of information (environmental versus health) does not seem crucial for the traveller choices. Then, in the next sections, we pool the two groups for studying the impact of regulatory interventions on the travellers' choices.

Now, we investigate the determinants of travellers' choices of means of transport through estimations. We use a multinomial logistic model on pooled data (2,394 observations). This model allows us to understand the effect of a series of variables on an unordered qualitative response variable (a variable that can take more than two values). ${ }^{18}$ With this model, we estimate the probability of belonging to an individual category (class). We consider here that the response variable is the traveller choice for a means of transport. We propose four class values for travellers' choices: Low-emission means of transport (public transport or/and rented electric vehicle); High-emission means of transport (taxi or/and personal vehicle); Low and High-emission means of transport, which corresponds to the case in which the traveller has the same preference for at least one low-emission means of transport and at least one high-emission means of transport ; No means of transport, which means that the traveller does not choose any means of transport. With the multinomial logit model, each category of the variable of interest will be compared to the reference mode. We take as reference the Low-emission means of transport class value. Then, we consider the same independent variables as for Table 6 . Table 7 presents the results of these estimates. ${ }^{19}$

\footnotetext{
${ }^{18}$ The multinomial logit model is a generalization of the logit model when the response variable has more than two categories. A logit model measures the relationship between the qualitative dependent variable and one or more independent variables by estimating probabilities using a logistic function, which is the cumulative logistic distribution.

${ }^{19}$ We only keep in Table 7 the significant results. See in Appendix the complete table.
} 


\begin{tabular}{|c|c|c|c|}
\hline $\begin{array}{l}\text { Class Value } \\
\text { Model: Multinomial logistic regression }\end{array}$ & $\begin{array}{c}\text { High-emission } \\
\text { means of transport }\end{array}$ & $\begin{array}{c}\text { Low and High-emission } \\
\text { means of transport }\end{array}$ & $\begin{array}{c}\text { No means of } \\
\text { transport }\end{array}$ \\
\hline Information on Environment (1/0) & $-0.061(0.258)$ & $-1.744 * * *(0.676)$ & $-0.132(0.327)$ \\
\hline Information on Environment First (1/0) & $-0.065(0.236)$ & $-1.528 * * *(0.519)$ & $-0.034(0.288)$ \\
\hline Message 2 & $-0.210(0.230)$ & $-2.147 * * *(0.573)$ & $-\mathbf{0 . 5 0 2} *(0.289)$ \\
\hline Having its health impacted by air pollution (1/0) & $\mathbf{0 . 2 6 0} * *(0.104)$ & $-0.132(0.355)$ & $-\mathbf{0 . 2 6 3 *}(0.147)$ \\
\hline Importance attached to the air pollution index-2 (-0) & $-\mathbf{0 . 5 5 2} * * *(0.155)$ & $0.256(0.467)$ & $-0.162(0.203)$ \\
\hline Importance attached to the air pollution index-3 (-0) & $-\mathbf{0 . 4 6 8} * * *(0.117)$ & $\mathbf{- 1 . 1 7 6} * * *(0.393)$ & $-\mathbf{0 . 4 7 3} * * *(0.160)$ \\
\hline Confidence on recommendation- $1(-0)$ & $\mathbf{0 . 3 7 3} * *(0.188)$ & $1.181 *(0.483)$ & $-\mathbf{0 . 4 3 7} *(0.247)$ \\
\hline Confidence on recommendation-2 (-0) & $\mathbf{0 . 3 3 3} * *(0.164)$ & $-1.317 * * *(0.484)$ & $-0.120(0.201)$ \\
\hline Confidence on recommendation-3 (-0) & $\mathbf{0 . 6 8 2} * * *(0.168)$ & $\mathbf{- 1 . 5 8 5 * * * ( 0 . 5 5 4 )}$ & $0.089(0.206)$ \\
\hline Income-2 (-0) & $0.213(0.172)$ & $1.467 *(0.814)$ & $0.309(0.231)$ \\
\hline Income-3 (-0) & $\mathbf{0 . 4 7 3} * * *(0.163)$ & $1.451 *(0.806)$ & $\mathbf{0 . 4 7 9} * *(0.222)$ \\
\hline Age & $\mathbf{0 . 0 2 1} * * *(0.003)$ & $0.001(0.012)$ & $\mathbf{0 . 0 1 2} * * *(0.004)$ \\
\hline $\operatorname{IDF}(1 / 0)$ & $0.359 * * *(0.127)$ & $-0.177(0.495)$ & $\mathbf{0 . 3 7 0} * *(0.169)$ \\
\hline Comfort as selection criteria instead of price $(1 / 0)$ & $0.047(0.098)$ & $-\mathbf{1 . 0 0 3} * * *(0.352)$ & $0.028(0.130)$ \\
\hline
\end{tabular}

Table 7: Results from a multinomial logistic regression about pooled travellers' choices for the mean of transport. ${ }^{*} p<0.1{ }^{* *} p<0.05 ;{ }^{* * *} p<0.01$. Standard errors in parentheses.

Travellers are likely to choose high-emission transport rather than low-emission transport according to the following probabilities: $1.297\left(e^{0.260}\right)$ less likely when their health has been impacted by air pollution than when it has not been; 0.576 and 0.626 times more likely when they have a high or very high interest in the air pollution index, respectively, than travellers who have no interest; 1.452, 1.395, and 1.978 times less likely when they have low, high, and very high trust on the recommendation, respectively, than travellers who do not; 1.605 times less likely when they are part of the highest salary bracket than the travellers who are part of the lowest; 1.021 times less likely when their age increases by one year; 1.432 times less likely when they live in the IDF area than when they do not live there.

Travellers hesitate between low-emission transport and high-emission transport rather than choosing low-emission transport with the following likelihood: $0.175\left(e^{-1.744}\right)$ times more likely when information that they first received relates to the environment rather than health; 0.217 times more likely when the information that they first received relates to the environment rather than to health; 0.117 times more likely when they received Message 2 than when they 
did not; 0.309 times more likely when they have a very high interest in the air pollution index than travellers who have no interest; 3.258 times less likely when they have low confidence for recommendations, and 0.268 and 0.205 times more likely when they have high and very high confidence, respectively, as opposed to travellers who do not have such confidence; 4.336 and 4.267 times less likely when they belong to the second and the first salary bracket, respectively, than when they belong to the lowest; 0.367 times more likely when they take more into account comfort to make their decision than when they consider price first.

Travellers prefer not to take any means of transport rather than choosing low-emission transport with the following likelihoods: $0.605\left(e^{-0.502}\right)$ times more likely when they received Message 2 than when they did not; 0.769 times more likely when their health has been impacted by air pollution than when it has not been ; 0.623 times more likely when they have a very high interest in the air pollution index as opposed to travellers who have no interest; 0.646 times more likely when they have low confidence for recommendations as opposed to travellers who do not have such confidence; 1.614 times less likely when they belong to the first salary bracket, respectively, than when they belong to the lowest; 1.012 times less likely when their age increases by one year; 1.448 times less likely when they live in the IDF area than when they do not live there.

\subsection{Regulatory interventions}

In France, the measures implemented for reducing air pollution are aimed at encouraging the use of low-emission vehicles. We postulate different regulatory intervention options for testing whether this goal is reached. We first suggest an information campaign, then a taxation of the high-emission means of transport (taxi and personal vehicle), a subsidy for the low-emission means of transport (rented electric vehicle and public transport), and finally a standard imposing the use of low-emission vehicles (rented electric vehicle and public transport). In fact, if a traveller chooses to take a taxi, the introduction of a tax on high-emission means of transport may change their choice. Indeed, the price of a taxi and of the use of a personal vehicle will increase by reducing the traveller surplus for the taxi and the personal vehicle to a level that may be lower than the traveller surplus for the low-emission means of transport. If instead of taxing, a subsidy on low-emission means of transport is implemented, the price of public transport and the rented electric vehicle will decrease. The traveller will have a higher surplus for these two means, which can exceed the surplus with the taxi. We then analyse the impacts of these four regulatory interventions on the respondents' decisions.

\subsubsection{Information campaigns}

We suppose that the regulator makes a complete information campaign on air pollution impacts on health and on the environment. For the moment, in France, information only concerns the level of pollution induced by the means of transport and not their health and environmental consequences. $\mathrm{CO}_{2}$ labelling of passenger vehicles was made compulsory in 2006 for new vehicles. It aims to educate buyers about vehicle emissions. Moreover, since October 1, 2013, passenger 
transport providers are required to provide information on the amounts of $\mathrm{CO}_{2}$ produced as a result of their services. The French law on Energy transition towards green growth, adopted on 17 August 2015, extends the mandatory $\mathrm{CO}_{2}$ information to all greenhouse gases. Here, we consider that public intervention consists in a very intense information campaign, perfectly understood by all travellers and revealing information on the damages of air pollution on health and the environment, which leads to round 7 .

Following this information campaign, travellers are perfectly informed. Travellers directly internalize all information provided by the campaign. Traveller i can choose between five outcomes: Taxi at price $\mathrm{P}(\mathrm{TAXI})$, public transport $(\mathrm{PT})$ at price $\mathrm{P}(\mathrm{PT})$, rented electric vehicle (REV) at price $\mathrm{P}(\mathrm{REV})$, personal vehicle $(\mathrm{PV})$ at price $\mathrm{P}(\mathrm{PV})$, or none of those. All prices are in Euros. We consider that choices on means of transportation are determined by traveller i's WTP for Taxi, PT, REV, and PV given by $W T P_{i 7} T A X I, W T P_{i 7} P T, W T P_{i 7} R E V$ and $W T P_{i 7} P V$, respectively. We assume that travellers may choose one means of transport if their WTP is higher than the price observed on the market. They thus choose to take the means of transport generating the highest utility (with a utility of non-used normalized to zero). Because complete information is perfectly internalized by travellers, no other tool can improve welfare. The per-unit surplus and welfare for participant $i \in N$ is as follows:

$$
W_{i}^{L}=\max \left\{0, W T P_{i 7} k-P(k) ; k \in\{T A X I, P T, R E V, P V\}\right\} .
$$

\subsubsection{A per-unit tax}

The public intervention consists in the adoption of a per-unit tax $\tau$ for the high-emission means of transport, which is taxi and personal vehicle. In France, the bonus malus system was implemented. It allows participating in the significant reduction in average $\mathrm{CO}_{2}$ emissions by subsidizing for low-emission transport and by taxing high-emission vehicles, which fell from $149 \mathrm{CO}_{2} \mathrm{~g} / \mathrm{km}$ in 2007 to $113 \mathrm{CO}_{2} \mathrm{~g} / \mathrm{km}$ in 2014. The amounts and thresholds are periodically revised to improve device performance. Since April 1, 2015, in the framework of the law on the energy transition to green growth, the schedule of bonus was reduced to $60 \mathrm{CO}_{2} \mathrm{~g} / \mathrm{km}$, favouring electric vehicles and public transport.

To simulate the tax scenario, we consider that travellers have no precise knowledge about the consequences of air pollution on health and the environment, which corresponds to the situation of round 1. Traveller i can choose between five outcomes: Taxi at price $P^{\tau}(T A X I)=P(T A X I)+\tau$ euro, public transport $(\mathrm{PT})$ at price $P^{\tau}(P T)=P(P T)$ euro, rented electric vehicle at price $P^{\tau}(R E V)=P(R E V)$ euro, personal vehicle at price $P^{\tau}(P V)=P(P V)+\tau$ euro, or neither. They take their mean of transport decision based on their surplus maximization, which is equal to:

$$
W_{i}^{\tau}(\tau)=\max \left\{0, W T P_{i 1} k-P^{\tau}(k)\right\}
$$

where $i \in N$ and $k \in\{T A X I, P T, R E V, P V\}$.

The regulator also considers the possible tax income coming from each respondent. The tax is only paid by travellers using a mean of transport with high-emission level (Taxi or Personal 
Vehicle). We note

$\mathbb{1}[k, i]=\left\{\begin{array}{l}1 \text { if traveller } i \text { chooses a mean of transport } k \text { with high-emission level (Taxi or PV); } \\ 0 \text { otherwise. }\end{array}\right.$

We note $n_{i}$ the additional number of mean of transport associated to the highest traveller $i$ surplus. That is if $l$ means of transport are associated to the highest traveller $i$ surplus, then $n_{i}=l-1$; if only one mean of transport is associated to the highest traveller $i$ surplus, then $n_{i}=0$; if none of the means of transport is associated with a positive traveller $i$ surplus, then $n_{i}=0$. The optimal tax $\tau^{*}$ is chosen by the regulator and is given by trial and error, maximizing the expected average welfare $\sum_{i=1}^{N}\left(W_{i}^{\tau}(\tau)+\left(\left(\sum_{k} \tau * \mathbb{1}[k, i]\right) /\left(n_{i}+1\right)\right)\right) / N$ over the $N=342$ respondents with $k \in\{T A X I, P T, R E V, P V\}$.

\subsubsection{A per-unit subsidy}

The public intervention consists in the adoption of a per-unit subsidy, s, for the low-emission means of transport that is public transport and rented electric vehicles. To simulate the subsidy scenario, we assume that travellers have no precise knowledge about the consequences of air pollution on health and the environment, which corresponds to the situation of round 1. Traveller i can choose between five outcomes: Taxi at price $P^{s}(T A X I)=P(T A X I)$ euro, public transport $(\mathrm{PT})$ at price $P^{s}(P T)=P(P T)-s$ euro, rented electric vehicle at price $P^{s}(R E V)=P(R E V)-s$ euro, personal vehicle at price $P^{s}(P V)=P(P V)$ euro, or neither. They choose their mean of transport based on their surplus maximization, which is equal to:

$$
W_{i}^{s}(s)=\max \left\{0, W T P_{i 1} k-P^{s}(k)\right\}
$$

where $i \in N$ and $k \in\{T A X I, P T, R E V, P V\}$.

The regulator also considers the possible subsidy expense. The subsidy only reduces the price paid by travellers who use a low-emission means of transport (Public Transport or Rented Electric Vehicle). We note:

$\mathbb{1}[k, i]=\left\{\begin{array}{l}1 \text { if traveller } i \text { chooses a mean of transport } \mathrm{k} \text { with low-emission level (PT or REV); } \\ 0 \text { otherwise. }\end{array}\right.$

We note $n_{i}$ the additional number of means of transport associated to the highest surplus for traveller $i$. The optimal subsidy $s^{*}$ is chosen by the regulator and is given by trial and error, maximizing the expected average welfare $\sum_{i=1}^{N}\left(W_{i}^{s}(s)-\left(\left(\sum_{k} s * \mathbb{1}[k, i]\right) /\left(n_{i}+1\right)\right)\right) / N$ over the $N=342$ respondents with $k \in\{T A X I, P T, R E V, P V\}$.

\subsubsection{A standard}

To simulate the standard scenario, we also assume that travellers have no precise knowledge about the consequences of air pollution on health and the environment, which corresponds to the situation of Round 1. Public intervention consists of leading people to use low-emission means of transport, that is to say public transport or rented electric vehicles. The City of Paris has organised a Day Without Polluting Vehicles every year since 2015. In addition, since January 23, 2017, an 'Air Quality Certificate' classifies vehicles into five categories according to 
age and therefore pollution level. This measure is meant to allow the regulator to incentivize traffic to one or more categories of transport. In such a situation, traveller i's means of transport decision is based on their surplus maximization, which is equal to:

$$
W_{i}^{S}=\max \left\{0, W T P_{i 1} k-P(k)\right\}
$$

where $i \in N$, and with $k \in\{P T, R E V\}$.

\subsubsection{Welfare analysis}

To perform the welfare analysis, we consider a baseline scenario in which the four means of transport are used without any additional regulation. This baseline welfare is defined by (2) with $\tau=0$. We compare the welfare effects of the different environmental policies.

We note $N$ the number of respondents, therefore $N=342$. We define the average variation in traveller surplus by $\Delta W_{N}^{L}=\sum_{i=1}^{N}\left[W_{i}^{L}-W_{i}^{\tau}(0)\right] / N$ for the information campaign. Then, we define the average variation in traveller surplus by $\Delta W_{N}^{\tau}\left(\tau^{*}\right)=\sum_{i=1}^{N}\left[W_{i}^{\tau}\left(\tau^{*}\right)-W_{i}^{\tau}(0)\right] / N$ for a $\operatorname{tax} \tau^{*}$, and $\Delta W_{N}^{s}\left(s^{*}\right)=\sum_{i=1}^{N}\left[W_{i}^{s}\left(s^{*}\right)-W_{i}^{\tau}(0)\right] / N$ for a subsidy $s^{*}$, and $\Delta W_{N}^{S}=$ $\sum_{i=1}^{N}\left[W_{i}^{S}-W_{i}^{\tau}(0)\right] / N$ for the mandatory standard. Finally, we compute the variation in expected number of travellers as the difference between the expected number of travellers for regulatory interventions and the expected number of travellers in the baseline scenario.

Our calculations use the market price observed for the different means of transport in February 2015 , that is $\mathrm{P}(\mathrm{TAXI})=€ 50$ for taxi, $\mathrm{P}(\mathrm{PT})=€ 10$ for public transport $(\mathrm{PT}), \mathrm{P}(\mathrm{REV})=€ 13.5$ for rented electric vehicle $(\mathrm{REV})$, and $\mathrm{P}(\mathrm{PV})=€ 3.7$ for personal vehicle $(\mathrm{PV}) .{ }^{20}$

Figure 6 presents the average variation in traveller surplus and the variation in expected number of travellers according to information campaigns, a per-unit tax, a per-unit subsidy, and a standard as described in the previous sections. We add to these regulatory interventions a new one, a tax-subsidy system. ${ }^{21}$ For the tax-subsidy system, we consider that traveller $i$ can choose between five outcomes: Taxi at price $P^{\tau \& s}(T A X I)=P(T A X I)+\tau$ euro, public transport $(\mathrm{PT})$ at price $P^{\tau \& s}(P T)=P(P T)-s$ euro, rented electric vehicle at price $P^{\tau \& s}(R E V)=P(R E V)-s$ euro, personal vehicle at price $P^{\tau \& s}(P V)=P(P V)+\tau$ euro, or neither. They take their means of transport decision based on their surplus maximization, which is equal to:

$$
W_{i}^{\tau \& s}(\tau, s)=\max \left\{0, W T P_{i 1} k-P^{\tau \& s}(k)\right\}
$$

where $i \in N$ and $k \in\{T A X I, P T, R E V, P V\}$.

The regulator also considers the possible tax income coming from each participant and the subsidy expense. We note:

$\mathbb{1}[k, i, \tau]=\left\{\begin{array}{l}1 \text { if traveller } i \text { chooses a mean of transport } \mathrm{k} \text { with high-emission level (Taxi or PV); } \\ 0 \text { otherwise. }\end{array}\right.$

\footnotetext{
${ }^{20}$ For more details, see footnote 6 .

${ }^{21}$ We have analysed a standard-subsidy system. However, we did not obtain a positive optimal subsidy combined with a standard
} 
and

$\mathbb{1}[k, i, s]=\left\{\begin{array}{l}1 \text { if traveller } i \text { chooses a mean of transport } \mathrm{k} \text { with low-emission level (PT or REV); } \\ 0 \text { otherwise. }\end{array}\right.$

We note $n_{i}$ the additional number of means of transport associated with the highest traveller $i$ surplus. The optimal tax-subsidy system $\left(\tau^{*}, s^{*}\right)$ is chosen by the regulator and is given by trial and error, maximizing the expected average welfare, which is equal to:

$\sum_{i=1}^{N}\left(W_{i}^{\tau \& s}(\tau, s)+\left(\sum_{k}(\tau * \mathbb{1}[k, i, \tau]-s * \mathbb{1}[k, i, s]) /\left(n_{i}+1\right)\right)\right) / N$ over the $N=342$ respondents with $k \in\{T A X I, P T, R E V, P V\}$.

We could obtain several solutions for the optimal tax subsidy system $\left(\tau^{*}, s^{*}\right)$. We have selected here the one which combined the positive expected impact of a per-unit tax and a perunit subsidy policy on traveller surplus (an increase) and the expected number of travellers (a decrease for high-emission means of transport, TAXI and PV, and an increase for low-emission means of transport, PT and REV). This allows us to show that a tax-subsidy system may be an interesting regulatory intervention. We define the average variation in traveller surplus by $\Delta W_{N}^{\tau \& s}\left(\tau^{*}, s^{*}\right)=\sum_{i=1}^{N}\left[W_{i}^{\tau \& s}\left(\tau^{*}, s^{*}\right)-W_{i}^{\tau}(0)\right] / N$ for a tax $\tau^{*}$ and a subsidy $s^{*}$.

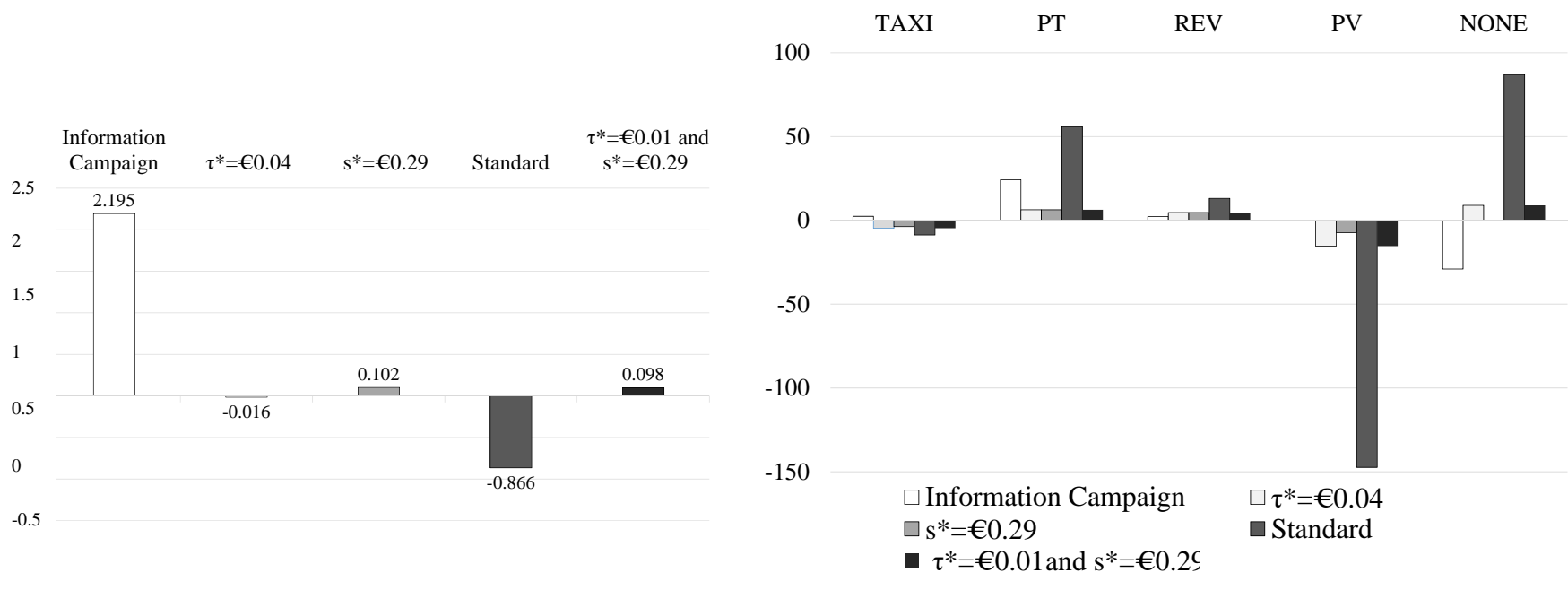

Figure 6: Average variation in traveller surplus in Euros (on the left) and variation in expected number of travellers (on the right) according to five regulatory interventions. 342 respondents (Group 1 and Group 2).

We first observe that information campaigns, a per-unit subsidy at $€ 0.29$ and the tax-subsidy system all lead to an increase in traveller surplus. In addition, all the regulatory interventions increase the number of travellers for low-emission means of transport but only information campaigns also increase high-emission ones. Finally, information campaigns and a per-unit subsidy at $€ 0.29$ decreases the number of travellers who will not choose any means or does not affect that number.

Next, we propose to analyse regulatory interventions after information campaigns, which is to say we combine information campaigns with the other regulatory interventions. Then, to simulate these scenarios, we assume that the regulator makes a complete campaign of infor- 
mation on air pollution impacts on health and on the environment and one of the regulatory interventions (tax, subsidy and standard). Following this information campaign, travellers are perfectly informed, which corresponds to the situation of Round 7. Therefore, traveller i's mean of transport decision is based on its surplus maximization, which is obtained by changing $W T P_{i 1}$ to $W T P_{i 7}$ in (2) for a per-unit tax, (3) for a per-unit subsidy, (4) for a standard, and (5) for a tax-subsidy system. The calculation of the optimal taxes and subsidies also takes into account the change. Figure 7 presents the average variation in traveller surplus and the variation in expected number of travellers according to the combined regulatory interventions. The tax-subsidy system follows the same criteria of selection as previously.

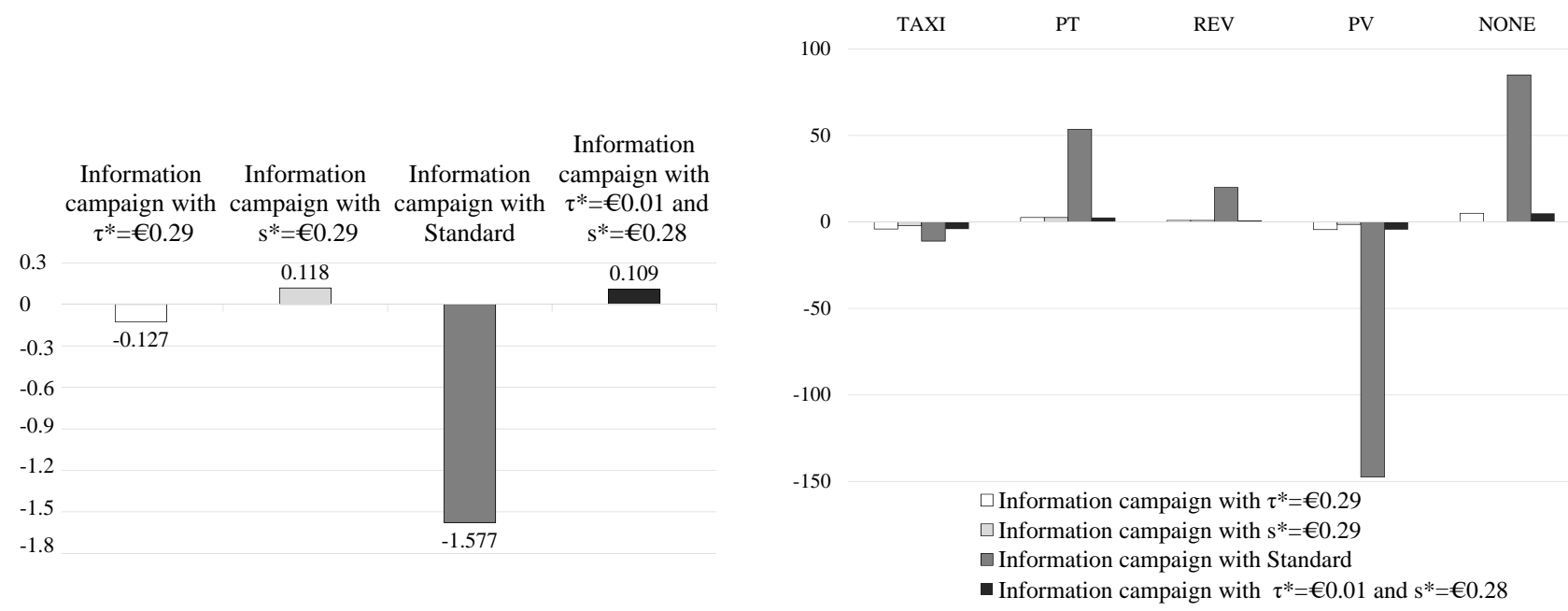

Figure 7: Average variation in traveller surplus in euro (on the left) and variation in expected number of travellers (on the right) according four regulatory interventions. 342 respondents (Group 1 and Group 2).

Information campaigns with a subsidy at $€ 0.29$ and information campaigns with a taxsubsidy system both increase the traveller surplus. All the combined regulatory interventions lead to an increase in the expected number of travellers for low-emission means of transport and a decrease for high-emission ones. However, only information campaigns with a subsidy at $€ 0.29$ does not change the number of travellers who do not choose any means of transport.

\subsubsection{Summary}

It is to be noted that the recommendations depend on the point of view that is adopted. From the traveller surplus point of view, we recommend to the health and the environmental regulator the policy, which leads the traveller surplus to increase with its implementation. From the point of view of the number of travellers, we recommend the policy, which increases the number of travellers for high-emission means of transport and decreases that number for high-emission means of transport. Finally, from the point of view of the number of travellers who do not take any means of transport, we recommend the policy that avoids the eviction of travellers on the means of transport market. In other words, we recommend the policy, which leads all travellers to choose at least one of the means of transport proposed. Table 8 sums up our results. 


\begin{tabular}{|c|c|}
\hline Point of view of & Policy recommended \\
\hline Traveller Surplus & $\begin{array}{l}\text { * Information Campaign } \\
\text { * A per-unit subsidy at } € 0.29 \\
\text { * A per-unit tax at } € 0.01 \text { and a per-unit subsidy at } € 0.29 \\
\text { * Information Campaign with a per-unit subsidy at } € 0.29 \\
\text { * Information Campaign with a per-unit tax at } € 0.01 \text { and } \\
\text { a per-unit subsidy at } € 0.28\end{array}$ \\
\hline $\begin{array}{l}\text { Increasing the number of } \\
\text { travellers for low-emission } \\
\text { means of transport and } \\
\text { decreasing the number of } \\
\text { travellers for high-emission } \\
\text { means of transport }\end{array}$ & $\begin{array}{l}\text { * A per unit tax at } € 0.04 \\
\text { * A per-unit subsidy at } € 0.29 \\
\text { * A standard } \\
\text { * A per-unit tax at } € 0.01 \text { and a per-unit subsidy at } € 0.29 \\
\text { * Information Campaign with a per-unit tax at } € 0.29 \\
\text { * Information Campaign with a per-unit subsidy at } € 0.29 \\
\text { * Information Campaign with standard } \\
\text { * Information Campaign with a per-unit tax at } € 0.01 \text { and } \\
\text { a per-unit subsidy at } € 0.28\end{array}$ \\
\hline $\begin{array}{l}\text { Reducing the number of } \\
\text { travellers who do not take any } \\
\text { means of transport }\end{array}$ & $\begin{array}{l}\text { * Information campaign } \\
\text { * A per-unit subsidy at } € 0.29 \\
\text { * Information Campaign with a per-unit subsidy at } € 0.29\end{array}$ \\
\hline
\end{tabular}

Table 8: Overview of the recommended policies.

Choosing between these policies will depend on regulators' priorities. However, we observe that with our survey a per-unit subsidy at $€ 0.29$ and an information campaign combined with a per-unit subsidy at $€ 0.29$ are recommended from every point of view under consideration.

\section{Conclusion}

In this paper, we have analysed travellers' for their means of transport. This is useful for choices by public authorities (health and environmental policies). While information matters, the order in which it is given does not. The information conveyed changes both travellers' willingness to pay and their choices. However, the use of high-emission vehicles has not diminished. Actually, it appears that the information campaign messages fail to decrease respondents' preferences for their personal vehicles. They can even lead them to increase that preference. From this study, we have then a better understanding of the non-adoption of low-emission vehicles after awareness campaigns. Actually, in our two groups, through the information campaign, the respondents increase on average their WTP for the personal vehicle. With a random effects model, we have analysed the determinants of the WTP for each means of transport. We have found that creating an interest for the air pollution index and giving more confidence to travellers in air pollution recommendations would increase the travellers' WTP for low-emission means of transport.

We have then analysed travellers' choices. We have seen that the personal vehicle is the most popular means of transport, before and after the information campaign. We have studied the determinants of traveller choice with a multinomial logit model. We have observed that improving travellers' confidence in air pollution recommendations would be a good way to lead travellers to choose low-emission transport rather than high-emission means. First, it would 
increase the WTP for public transport; second, it would increase the likelihood of travellers choosing a low-emission means of transport over high-emission transport. In addition, we show that users who attach great importance to comfort are less likely than those who value the price to choose low-emission vehicles. Individual interest can then prevail over the collective interest, thus verifying the theory of the tragedy of the commons. Improving comfort, especially in public transport, could be a way to encourage travellers to use low-emission means of transport.

Finally, concerning regulatory discussions, we have tested different policies (taxes, subsidies, standards and a tax-subsidy system with and without information campaign) to encourage people to adopt low-emission vehicles. Choosing between these policies will depend on regulator's priorities. However, two of these policies seem to be good alternatives: the subsidy of lowemission vehicles with and without information campaigns. This result supports the actual policies taken on the reduction of air pollution by the mayor of Paris.

Although this study may be replicated, our paper presents some limitations. First, as in all WTP approaches, there might be a hypothetical bias in our study. As suggested by Lusk (2003), we have tried to reduce this bias with a cheap talk detailing to respondents the means of transport we were presenting to them and explaining to them the goal of the study. Second, we did not consider controversies or incorrect messages leading to respondents' confusion or misunderstanding. To correct this, we would introduce a probability of being wrongly informed $\delta$, namely a probability of having respondents misunderstand information regarding means of transport, such that the average variation in traveller surplus for information campaign would become $\sum_{i=1}^{N}\left[(1-\delta) W_{i}^{L}-\delta W_{i}^{\tau}(0)\right] / N$. This assumption would decrease the traveller surplus. Third, the way to collect data might be discussed. We have used an online study. Cobanoglu et al (2001), Couper (2000), and McDonald and Adam (2003) highlight that online studies allow to save time and efforts in collecting data. Moreover, Fricker et al (2005), Kreuter et al (2008) and Heerwegh and Loosveld (2008) show that online studies make it possible to obtain higher quality answers with fewer 'Don't know' and unanswered questions than telephone surveys and personal interview surveys. Therefore, on the quality of data collection, online studies do not seem to present more disadvantages than other kinds of surveys. Finally, for further research, it might be interesting for this subject to be treated with other experimental methods such as discrete choice theory. 


\section{Appendix}

Message 1: A ride from the center of Paris (Châtelet Metro station) to Roissy Charles de Gaulle Airport by taxi costs about $€ 50, € 10$ by public transport, $€ 13.50$ in a rented electric vehicle (Autolib type) and $€ 3.70$ in a personal vehicle.

Message 2: According to the WHO (World Health Organization): 'Breathing clean air is considered essential for health and well-being of man. However, the air pollution continues to pose a major threat in terms of health around the world. [...] More than 2 million premature deaths each year can be attributed to the effects of outdoor air pollution in cities [...] worldwide.'

Message 3: In France, 42,000 premature deaths, including 1,400 in Paris in 2011 are attributed to pollution. According to the latest report of the European Environment Agency, nearly 400,000 deaths in Europe related to air pollution.

Message 4: If fine particles levels were in compliance with WHO quality targets $\left(10 \mu \mathrm{g} / \mathrm{m}^{3}\right.$ as an annual average), Parisians and persons from the suburbs would gain six months of life expectancy. In 2013, the average fine particle levels was $26 \mu \mathrm{g} / \mathrm{m}^{3}$, more than double of what is recommended.

Message 5: The Ministry of Ecology, Sustainable Development and Energy estimated in 2012 that health costs of air pollution outdoors in France rose annually by 20 to 30 billion $€$, which corresponds to about 400 to $500 € /$ year/person.

Message 6: Air pollution induced corrosion due to sulphur dioxide, blackening and crusts of buildings by dust from the combustion of petroleum products, as well as various changes in combination with the gel, moisture and microorganisms.

Message 7: Air pollution is caused by the emission of components of different kinds into the atmosphere. While they are issued locally (at a city for example), these pollutants have consequences both at local, regional and global ('acid rain', which alter ecosystems, contributing to the effect greenhouse and global warming). 


\begin{tabular}{|c|c|c|c|c|}
\hline $\begin{array}{l}\text { Endogenous variable } \\
\text { Model: Random effects model }\end{array}$ & $\begin{array}{l}\text { Pooled Willingness } \\
\text { To Pay for Taxi in } €\end{array}$ & \begin{tabular}{|c|} 
Pooled Willingness \\
To Pay for Personal \\
Vehicle in $€$ \\
\end{tabular} & $\begin{array}{c}\text { Pooled Willingness To } \\
\text { Pay for Rented } \\
\text { Electric Vehicle in } €\end{array}$ & $\begin{array}{c}\text { Pooled Willingness To } \\
\text { Pay for Public } \\
\text { Transport in } €\end{array}$ \\
\hline Constant & $26.551 * *(13.279)$ & $2.368(4.211)$ & $14.324(5.633)$ & $7.511 *(4.174)$ \\
\hline Information on Environment $(1 / 0)$ & $\mathbf{- 2 . 1 8 5 * * * ( 0 . 6 6 7 )}$ & $0.104(0.215)$ & $-0.428(0.325)$ & $-0.041(0.265)$ \\
\hline Information on Environment First (1/0) & $-0.373(1.536)$ & $-0.226(0.488)$ & $-0.207(0.664)$ & $-0.577(0.500)$ \\
\hline Message 2 & $-\mathbf{3 . 0 5 9} * * *(0.590)$ & $0.293(0.190)$ & $0.248(0.288)$ & $0.607 * * *(0.234)$ \\
\hline Message 3 & $\mathbf{- 0 . 8 4 5 * ( 0 . 4 6 9 )}$ & $0.129(0.151)$ & $-0.119(0.229)$ & $-0.127(0.186)$ \\
\hline Message 4 & $-0.489(0.469)$ & $-0.013(0.151)$ & $0.013(0.229)$ & $0.190(0.186)$ \\
\hline Message 5 & $-0.087(0.447)$ & $0.170(0.144)$ & $0.047(0.218)$ & $0.037(0.177)$ \\
\hline Message 6 & $1.395(0.849)$ & $-0.060(0.273)$ & $0.496(0.414)$ & $0.333(0.337)$ \\
\hline Message 7 & $0.143(0.469)$ & $0.236(0.151)$ & $-0.166(0.229)$ & $0.292(0.186)$ \\
\hline Having its health impacted by air pollution (1/0) & $2.731 *(1.537)$ & $-0.457(0.487)$ & $-0.613(0.652)$ & $0.394(0.483)$ \\
\hline Importance attached to the air pollution index-1 (-0) & $-1.624(4.027)$ & $0.887(1.277)$ & $2.450(1.708)$ & $-0.794(1.265)$ \\
\hline Importance attached to the air pollution index-2 (-0) & $0.201(2.252)$ & $0.285(0.714)$ & $1.953 * *(0.955)$ & $0.749(0.707)$ \\
\hline Confidence on recommendation-1 $(-0)$ & $-0.954(2.701)$ & $0.297(0.856)$ & $-0.942(1.145)$ & $1.559(0.848)$ \\
\hline Confidence on recommendation-2 (-0) & $0.308(2.347)$ & $0.912(0.744)$ & $-1.302(0.995)$ & $1.100 *(0.737)$ \\
\hline Confidence on recommendation-3 (-0) & $-0.771(2.379)$ & $0.744(0.754)$ & $-0.999(1.009)$ & $0.329(0.747)$ \\
\hline Gender $(1 / 0)$ & $-0.176(1.404)$ & $-0.462(0.445)$ & $0.041(0.595)$ & $-0.126(0.441)$ \\
\hline Income-1 (-0) & $0.017(2.662)$ & $-0.097(0.844)$ & $-0.923(1.129)$ & $0.088(0.836)$ \\
\hline Income-2 (-0) & $-2.916(2.548)$ & $-1.267(0.808)$ & $-1.618(1.081)$ & $0.222(0.800)$ \\
\hline Income-3 (-0) & 3.117 (2.429) & $-0.883(0.770)$ & $-1.285(1.030)$ & $0.045(0.763)$ \\
\hline Age & $0.070(0.051)$ & $-0.559(0.454)$ & $\mathbf{- 0 . 0 4 9} * *(0.022)$ & $-0.010(0.016)$ \\
\hline SPC-1 (-0) & $-8.141(13.342)$ & $1.621(4.231)$ & $-1.750(5.659)$ & $-0.848(4.192)$ \\
\hline SPC-2 (-0) & $-3.601(12.840)$ & $1.975(4.072)$ & $1.017(5.446)$ & $0.220(4.035)$ \\
\hline SPC-3 (-0) & $-1.841(12.837)$ & $1.495(4.071)$ & $0.564(5.445)$ & $-0.314(4.034)$ \\
\hline SPC-4 (-0) & $-2.386(12.849)$ & $1.782(4.075)$ & $0.253(5.450)$ & $-0.261(4.037)$ \\
\hline IDF (1/0) & $1.151(1.837)$ & $0.816(0.582)$ & $-0.610(0.779)$ & $-0.482(0.577)$ \\
\hline Comfort as selection criteria instead of price $(1 / 0)$ & $1.443(1.432)$ & $-0.014(0.016)$ & $0.273(0.607)$ & $0.076(0.450)$ \\
\hline Observations & 2.394 & 2.394 & 2.394 & 2.394 \\
\hline
\end{tabular}

Table 9: Results from Random effects panel model about pooled WTPs in levels. ${ }^{*} p<0.1 ;{ }^{* *} p<0.05$; ${ }^{* * *} p<0.01$. Standard errors in parentheses. Complete table. 


\begin{tabular}{|c|c|c|c|}
\hline $\begin{array}{l}\text { Class Value } \\
\text { Model: Multinomial logistic regression }\end{array}$ & $\begin{array}{c}\text { High-emission } \\
\text { means of transport }\end{array}$ & $\begin{array}{l}\text { Low and High-emission } \\
\text { means of transport }\end{array}$ & $\begin{array}{l}\text { No means of } \\
\text { transport }\end{array}$ \\
\hline Constant & $-2.045(161609)$ & $0.709(360670)$ & $24.691(118396)$ \\
\hline Information on Environment (1/0) & $-0.061(0.258)$ & $-1.744 * * *(0.676)$ & $-0.132(0.327)$ \\
\hline Information on Environment First (1/0) & $-0.065(0.236)$ & $-1.528 * * *(0.519)$ & $-0.034(0.288)$ \\
\hline Message 2 & $-0.210(0.230)$ & $-2.147 * * *(0.573)$ & $\mathbf{- 0 . 5 0 2} *(0.289)$ \\
\hline Message 3 & $0.037(0.172)$ & $0.191(0.596)$ & $0.023(0.236)$ \\
\hline Message 4 & $-0.112(0.172)$ & $-0.058(0.575)$ & $-0.083(0.236)$ \\
\hline Message 5 & $0.124(0.164)$ & $0.309(0.525)$ & $0.079(0.224)$ \\
\hline Message 6 & $-0.134(0.325)$ & $1.374(0.880)$ & $-0.115(0.414)$ \\
\hline Message 7 & $0.095(0.173)$ & $-0.440(0.570)$ & $-0.096(0.232)$ \\
\hline Having its health impacted by air pollution (1/0) & $\mathbf{0 . 2 6 0} * *(0.104)$ & $-0.132(0.355)$ & $-\mathbf{0 . 2 6 3 *}(0.147)$ \\
\hline Importance attached to the air pollution index-1 (-0) & $-0.388(0.272)$ & $-21.855(15494)$ & $0.228(0.357)$ \\
\hline Importance attached to the air pollution index-2 (-0) & $\mathbf{- 0 . 5 5 2} * * *(0.155)$ & $0.256(0.467)$ & $-0.162(0.203)$ \\
\hline Importance attached to the air pollution index-3 (-0) & $\mathbf{- 0 . 4 6 8 * * * ( 0 . 1 1 7 )}$ & $-\mathbf{1 . 1 7 6} * * *(0.393)$ & $\mathbf{- 0 . 4 7 3 * * * ( 0 . 1 6 0 )}$ \\
\hline Confidence on recommendation- $1(-0)$ & $\mathbf{0 . 3 7 3} * *(0.188)$ & $1.181 * *(0.483)$ & $\mathbf{- 0 . 4 3 7 * ( 0 . 2 4 7 )}$ \\
\hline Confidence on recommendation-2 (-0) & $\mathbf{0 . 3 3 3} * *(0.164)$ & $-1.317 * * *(0.484)$ & $-0.120(0.201)$ \\
\hline Confidence on recommendation- $3(-0)$ & $\mathbf{0 . 6 8 2} * * *(0.168)$ & $-1.585 * * *(0.554)$ & $0.089(0.206)$ \\
\hline Gender $(1 / 0)$ & $0.086(0.096)$ & $-0.116(0.290)$ & $-0.087(0.128)$ \\
\hline Income-1 (-0) & $0.163(0.179)$ & $0.871(0.841)$ & $0.152(0.241)$ \\
\hline Income-2 (-0) & $0.213(0.172)$ & $1.467 *(0.814)$ & $0.309(0.231)$ \\
\hline Income-3 (-0) & $\mathbf{0 . 4 7 3} * * *(0.163)$ & $\mathbf{1 . 4 5 1} *(0.806)$ & $\mathbf{0 . 4 7 9} * *(0.222)$ \\
\hline Age & $\mathbf{0 . 0 2 1} * * *(0.003)$ & $0.001(0.012)$ & $\mathbf{0 . 0 1 2} * * *(0.004)$ \\
\hline SPC-1 (-0) & $1.762(161609)$ & $-2.134(360670)$ & $-24.570(118396)$ \\
\hline SPC-2 (-0) & $0.852(161609)$ & $-2.289(360670)$ & $-25.867(118396)$ \\
\hline SPC-3 (-0) & $0.801(161609)$ & $-0.837(360670)$ & $-25.624(118396)$ \\
\hline SPC-4 (-0) & 1.019 (161609) & $-3.153(360670)$ & $-25.312(118396)$ \\
\hline $\operatorname{IDF}(1 / 0)$ & $\mathbf{0 . 3 5 9} * * *(0.127)$ & $-0.177(0.495)$ & $\mathbf{0 . 3 7 0} * *(0.169)$ \\
\hline Comfort as selection criteria instead of price (1/0) & $0.047(0.098)$ & $\mathbf{- 1 . 0 0 3} * * *(0.352)$ & $0.028(0.130)$ \\
\hline
\end{tabular}

Table 10: Results from a multinomial logistic regression about pooled travellers' choices for the mean of transport. ${ }^{*} p<0.1{ }^{* *} p<0.05 ;{ }^{* * *} p<0.01$. Standard errors in parentheses. Complete table. 


\section{References}

1. Agostinia, C.A., Jimnez, J. 2015. The distributional incidence of the gasoline tax in Chile. Energy Policy 85, 243-252.

2. Airparif (2016). Surveillance et information sur la qualité de l'air en Île de France - Bilan année 2015.

3. Baidoo, I.K., Nyarko, E. 2015. Stated Preference Modeling for a Preferred Transportation Mode. Mathematical Theory and Modeling.

4. Bollena, J., Brink, C. 2014. Air pollution policy in Europe: Quantifying the interaction with greenhouse gases and climate change policies. Energy Economics 46, 202-215.

5. Chemarin, S.; Orset, C. 2011. Innovation and information acquisition under time inconsistency and uncertainty. Geneva Risk and Insurance Review 36, 132-173.

6. Cobanoglu, C., Warde, B., Moreo, P. 2001. A comparison of mail, fax, and Web-based survey methods. International Journal of Market Research, 43(4), 405-410.

7. Couper, M.P. 2000. Web surveys: A review of issues and approaches. The Public Opinion Quarterly, 64 (4), 464-494.

8. Douglas, W., Dockery, C., Pope, A., Xu, X., Spengler, J.D, Ware, J.H., Fay, M.E., Ferris, B.J., Speizer, F.E. 1993. An Association between Air Pollution and Mortality in Six U.S. Cities. The New England Journal of Medecine 329:1753-1759.

9. Fricker, S., Galesic, M., Tourangeau, R., Yan, T. 2005. An experimental comparison of Web and telephone surveys. The Public Opinion Quarterly, 69(3), 370-392.

10. Greene, W.H. (2017). Econometric Analysis, 8th Edition. Pearson.

11. Heerwegh, D., Loosveldt, G. 2008. Face-to-face versus Web surveying in a high-Internet coverage population: differences in response quality. The Public Opinion Quarterly, 72(5), 836-846.

12. Hensher, D. A. 1994. Stated preference analysis of travel choices: The state of practice. Transportation 21(2), 107-133.

13. Kotchena, M.J., Boylec, K.J., Leiserowitza, A.A. 2013. Willingness-to-pay and policyinstrument choice for climate-change policy in the United States. Energy Policy 55, 617625.

14. Kreuter, F., Presser, S., Tourangeau, R. 2008. Social desirability bias in CATI, IVR, and Web surveys: The effects of mode and question sensitivity. The Public Opinion Quarterly, $72(5), 847-865$. 
15. Krewski, D., Burnett, R.T., Goldberg, M.S., Hoover, K., Siemiatycki, J., Abrahamowicz, M., White, W.H. 2004. Validation of the Harvard Six Cities Study of particulate air pollution and mortality. The New England Journal of Medecine 8;350(2):198-9.

16. Kroes, E.P., Sheldon, R.J. 1988. Stated Preference Methods: An Introduction. Journal of Transport Economics and Policy, 22, No. 1, 11-25.

17. Louviere, J.J., Hensher, D.A., Swait, J.D. 2000. Stated Choice Methods, Analysis and Applications. Cambridge University Press.

18. Lusk, J.L. 2003. Effects of cheap talk on consumer willingness to pay for golden rice. American Journal of Agricultural Economics, 85, No. 4, 840-856.

19. McDonald, H., Adam, S. 2003. A comparison of online and postal data collection methods in marketing research. Marketing Intelligence and Planning, 21(2), 85-95.

20. Montag, J. 2015. The simple economics of motor vehicle pollution: A case for fuel tax. Energy Policy 85, 138-149.

21. Naqvi, A., Zwickl, K. 2017. Fifty shades of green: Revisiting decoupling by economic sectors and air pollutants. Ecological Economics 133, 111-126.

22. Petrik, O., de Abreu e Silva, J., Moura, F. 2016. Stated preference surveys in transport demand modeling: disengagement of respondents. The International Journal of Transportation Research, 8(1), 13-25.

23. Pope, C.A., Ezzati, M., Dockery, D.W. 2009. Fine-particulate air pollution and life expectancy in the United States. The New England Journal of Medecine, 360:376-386.

24. Suna, C., Yuana, X., Yaoa, X. 2016. Social acceptance towards the air pollution in China: Evidence from public's willingness to pay for smog mitigation. Energy Policy 92, 313-324.

25. Tanizaki, H. (2004). Computational Methods in Statistics and Econometrics. CRC Press.

26. Timmers, V.R.J.H., Achten, P.A.J. 2016. Non-exhaust PM emissions from electric vehicles. Atmospheric Environment 134, 10-17.

27. Wardman, M.A. 1988. Comparison of Revealed Preference and Stated Preference Models of Travel Behaviour. Journal of Transport Economics and Policy, 22, No.1, 71-91.

28. Wanga, Y., Mingxing, S., Yanga, X., Yuanc, X. 2016. Public awareness and willingness to pay for tackling smog pollution in China: a case study. Journal of Cleaner Production $112,1627-1634$. 